JAN 2591915

\title{
ZUR ENTWICKLUNGSGESCHICHTEE DES
}

POLYEMBRYONALEN CHALCIDIERS AGENIASPIS

\section{(ENCYRTUS) PUSCICOLLIS DALM}

\section{INAUGURAL-DISSERTATION}

ZOR ERLANGUNG DER DOKTORWÜRDE

DER HOHEN PHILOSOPHISCHEN FAKULTÄT

DER UNIVERSITÄT LEIPZIG

\author{
VORGELEGT
}

voN

FRIEDRICH MARTIN

AUS WENDISCH-ROTTMANNSDORF

(AMTSH. ZWICKAU)

MIT 8 FIGUREN IM TEXT UND TAFEL X'V UND XVI

LEIPZIG UND BERLIN

WILHELM ENGELMANN 
Angenommen von der III. Sektion auf Grund der Gutachten der Herren CHuN und Pfeffer.

Leipzig, den 29. November 1913.

Der Procancellar

Kirchner

Sonderabdruck aus: ,Zeitschrift für wissenschaftl. Zoologie•, Bd. CX, Heft 3. 
M36z

MEINEN ELTERN GEWIDMET 


\section{Inhalt.}

Einleitung . . . . . . . . . . . . . . . . . 420

Material und Technik . . . . . . . . . . . . . . . 422

Entwicklungsgeschichtliches . . . . . . . . . . . . . . 425

I. Das Ei im Orarium . . . . . . . . . . . . . . 425

I. Die Morphologie des weiblichen Geschlechtsapparates . . . . 425

2. Der Bau der Ovarialtuben............ . . 427

3. Das wachsende $\mathrm{Ei}$. . . . . . . . . . . . . 429

Anhang: Zusammenfassung der Vorgänge innerhalb des wachscnden Eies ... . . . . . . . . 435

II. Das Ei im Hyponomeuta-Ei . . . . . . . . . . . . . 436 Morphologisches:

1. Das Vorei . . . . . . . . . . . . . . 436

2. Die Reifung ... . . . . . . . . . . . 437

3. Die Befruchtung ............... . . 443

4. Die erste Furchung . . . . . . . . . . . . . 443

5. Die zweite Furchung und die folgenden......... . 447 Biologisches:

1. Dic Zeit | der Infektion, bezogen auf den Hyponomeuta-Em-

2. Der Ort $\}$ bryo. (Degeneration der Eier im Dotter) . . . 450

III. Das Ei in der IIyponomeuta-Raupe (ror dem Eintritt der Polyembryonie, August-April) . . . . . . . . . . 456

IV. Der Polyembryo (Geschlechtszellen - Bakterien im Keimschlauch) 460

V. Die postembryonale Entwicklung . . . . . . . . . . . . . 462

Biologisches: Lebensweise - Anzahl; Größe; Verhältnis der Geschlechter -

Parthenogenese - Feinde - Verbreitung der Art . . . . . . . 463 
Seite

Erklärung der Polyembryonie . . . . . . . . . . 469

Verhalten der Richtungskörper . . . . . . . . . 471

Die Furchung. . . . . . . . . . . . . . . 472

Der Nucleolus . . . . . . . . . . . . . 472

Zusammenfassung . . . . . . . . . . . . . . 474

Literaturverzeichnis . . . . . . . . . . . . . . . . 475

Erklärung der Abbildungen . . . . . . . . . . . . . 477

\section{Einleitung.}

Mit der Entwicklungsgeschichte des Chalcidiers Ageniaspis (Encyrtus) fuscicollis (Dalm.) Thoms. beschäftigt sich als erster E. Bugrion in einer 1891 erschienenen Arbeit. Und zwar geht er aus von den eigentümlichen »Keimschläuchen «, die in Raupen der Hyponomeuta cognatella Hb. gefunden werden: 50-100 Embryonen liegen hintereinander in eine gemeinsame Nährmasse eingebettet; diese ist von einem Epithel umgeben, das sich Bugnion aus der Verschmelzung der amniotischen Hüllen der Einzelembryonen entstanden denkt und das außen noch eine Cuticula abgeschieden hat. Da die Embryonen eines Keimschlauchs in der Hälfte der Fälle Individuen desselben Geschlechts liefern, so nimmt Bugnion an, daß ein mütterliches Insekt die Raupe kurz nacheinander mit 50-100 Eiern belegt haben müsse. Eine ausführliche Darstellung der Anatomie der Imago beschließt die Arbeit Bugnions.

1904 veröffentlicht dann P. MarchaL die bereits 1898 in einer vorläufigen Mitteilung angekündigte Tatsache: alle die in einem Keimschlauch enthaltenen Embryonen der Ageniaspis samt ihrer Nährmasse, dem »Trophamnios « sind ans einem einzigen Ei entstanden. Ein Teil der Eier und die darin gelegenen Kerne liefern durch fortgesetzte Teilungen zahlreiche Blastomeren; diese zerfallen secundär in einzelne Morulae und jede von diesen entwickelt sich zn einem Embryo. Der andre Teil des Eies samt seinen Kernen ist der Ursprung des Trophamnios und seines großen Kerns, des »Paranucleus«. Die epitheliale Hülle ist ein Produkt der Wirtsraupe. Diese bisher unbekannte Art der Vermehrung nennt Marchal »Polyembryonie «. (Die von BraNDES [1898] vorgeschlagene Bezeichnung 》Germinogonie « hat, soviel ich aus der Literatur ersehe, die Originalbezeichnung Marchals nicht zu verdrängen vermocht.) Das Ei des Chalcidiers ist nicht in die Raupe, sondern in das Ei der Hyponomeuta gelegt worden. 
Schließlich gibt uns F. Silvestri (1909) weitere Aufklärung über die Entwicklungsgeschichte der Ageniaspis fuscicollis von Hyponomeuta sowohl, als auch der von Prays oleellus Fbr., zwei biologische Rassen, die, von unwichtigen Abweichungen abgesehen, in ihrer Entwicklungsgeschichte übereinstimmen. Er findet folgendes: das parthenogenetische und das befruchtete $\mathrm{Ei}$ entwickeln sich in gleicher Weise; die Befruchtung bestimmt wahrscheinlich das weibliche Geschlecht. "L'ovo allo stato di ovocite di $1^{\circ}$ ordine completamente sviluppato ha un nucleolo separato dalla cromatina del nucleo «, also eine Art Dotterkern, der vom Keimbläschen abgeleitet wird. Die den Eikern enthaltende » parte embryonale « des reifen Eies furcht sich total: es entstehen so die Blastomeren bzw. die Embryonen; die die Richtungskörper enthaltende »parte polare «dagegen liefert das Trophamnios, die Richtungskörper verschmelzen zum Paranucleus. Der "Nucleolus « schließlich wird in eine der beiden ersten Furchungszellen aufgenommen, er bewirkt Teilungshemmungen der von ihr abstammenden Zellen, ist aber bald nicht mehr nachweisbar.

Diese Beobachtungen Silvestris sind so abweichend von allem, was wir aus der Entwicklungsgeschichte überhaupt liennen (wenn wir den von dem gleichen Autor untersuchten Chalcidier Litomastix truncatellus [1906] beiseite lassen), daß eine erneute Untersuchung unsres Gegenstandes gerechtfertigt ist. Das gilt insbesondre von dem eigenartigen Geschick der Richtungskörper, ebenso von der "partiell totalen «Furchung. Vor allem aber sind über Herkunft, Natur und Schicksal des "Nucleolus « noch eingehendere Aufschliisse notwendig. - Daneben clrängten sich Fragen biologischer Natur auf: welches Geschlecht liefern die parthenogenetischen Eier? Wie gestaltet sich das Verhältnis zwischen dem Parasiten und den Elementen des Wirtseies, bzw. der Wirtsraupe?

Ausgeführt wurde die vorliegende Untersuchung im Zoologischen Institut der Universität Leipzig und zu Beginn des Sommersemesters 1909 angefangen. Sie geht zurück auf eine Anregung von Herrn Prof. Dr. O. zUR Strassen, dem ich mich für sein reges Interesse zu herzlichem Dank verpflichtet fühle. Daneben gilt mein Dank insbesondre Herm Prof. C. Chun und Herrn Privatdozent Dr. O. Steche, die stets in liebenswiirdigster Weise bereit waren, mich bei meiner Arbeit zu fördern und zu unterstïtzen. Auch den Herren Prof. Dr. H. Siмroth, Prof. Dr. R. Wolterech und Privatdozent Dr. F. Hempeluaxis sei für ihr anregendes Interesse bestens gedankt. 


\section{Material und 'Technik.}

Für meine Untersuchungen habe ich diejenige Ageniaspis fuscicollis verwendet, die in der Hyponomeuta cognatella $\mathrm{Hb}$. des Pfaffenhütchens Evonymus europaea L. schmarotzt.

Es empfiehlt sich vielleicht zur allgemeinen Orientierung gleich an dieser Stelle die Naturgeschichte der Schlupfwespe, bzw. der Hyponomeuta ganz kurz zu beschreiben: Ende Juli-Anfang August legen die Ageniaspis- + ihre Eier in die der Hyponomeuta, die zu Paketen von 20-40 Stück vereinigt an die Rinde der Evonymuszweige angeklebt werden. Im Herbst noch schlüpfen die Räupchen ans; sie bleiben aber während des Winters unter ihren als Schutzdecke dienenden Eihüllen. Erst im Frühjahr, wenn die Evonymuszweige austreiben, kriechen sie an die jungen Triebe und wachsen nun rasch heran. Im Mai etwa haben sich die Ageniaspis-Eier zu den Keimschläuchen entwickelt. Ende Juni verpuppen sich die Raupen, bzw. die Ageniaspislarven, die, inzwischen herangewachsen, das Innere der Raupen erfüllen. Einige Zeit nachdem die Schmetterlinge geschlïpft sind, verlassen auch die Ageniaspis ihre Puppenhüllen, bereit, die frischen Hyponomeutagelege zu infizieren.

Die an den Rändern der Leipziger Auwaldungen häufigen Evonymus waren gewöhnlich stark mit Hyponomeuten besetzt und eine Untersuchung der Raupen ergab, daß so viele von ihnen Keimschläuche enthielten, daß es nicht eben schwer hielt, hinreichendes Material an Larven und auch — da die Hyponomeuten sich ohne jede Schwierigkeit ziehen lassen —an Puppen und ausgebildeten Tieren zu bekommen.

Um aber die allerersten Entwicklungsstadien vom frisch gelegten Ei an in möglichst geschlossener Serie zu erlangen, erwies es sich als notwendig, die Ageniaspis zu züchten. Marchal beschreibt ausführlich die Zucht der in der Hyponomeuta mahalebella Guénée des Prunus mahaleb L. schmarotzenden Ageniaspis fuscicollis und seiner Anleitung im Prinzip folgend bin ich folgendermaßen verfahren:

im Mai wurden möglichst viele Mottennester eingetragen und die gefräßigen Raupen großgezogen. Zur Verpuppung suchen die erwachsenen Raupen das Dunkle auf und spinnen sich ein, ausgenommen die befallenen Individuen, die ihre Larvenhaut behalten und sich mit einem nur spärlichen Gespinst umgeben; mit vielen, kleinen Buckeln, die den im Innern liegenden Ageniaspis-»Puppenwaben « entsprechen, bedeckt, hängen sie charakteristisch krumm und vertrocknet da. 
Übereinstimmend mit Bugnion habe ich beobachtet, daß es nicht mit Sicherheit möglich ist, vor der Verpuppung die infizierten Raupen von den normalen zu unterscheiden, weder die Farbe, noch der Leibesumfang, noch die Lebensgewohnheiten geben genügenden Anhalt. MARCHAL dagegen vermochte die Raupen von mahalebella, die freie Larven enthielten, leicht herauszufinden.

Die infizierten Raupen wurden ausgelesen und in Glastuben verwahrt.

Un mun sowohl dem Wirtsschmetterling als auch dem Chalcidier zusagende Lebensbedingungen zu gewähren, ist es durchaus nötig, einen eingewachsenen Evonymusstrauch zum Ansetzen der Zucht zu benutzen. (An abgeschnittene Zweige legen zwar die Hyponomeuten ihre Eier ab, die Ageniaspis aber stechen nicht an). Herr Prof. CHun war so liebenswürdig, mir einen Strauch in seinem Garten zur Verfügung zu stellen. Von diesem Strauch wurde ein etwa in Brusthöhe abgehender Ast in eine Art Zelt aus Mull eingeschlossen; die eine Wand bestand aus einem Fenster, dessen einer Flügel als Eingangstür diente. Das Ganze war groß genug, daß man darin stehen und hantieren und die Tiere direkt beobachten komte. Ein ïberall fester Abschluß des Mulls ist sehr wichtig, um die Forficuliden fermzuhalten, die durch Zerfressen der Gelege außerordentlich lästig fallen.

Anfang Juli beginnen die Hyponomeuten zu schlïpfen und nun wurden die Schmetterlinge in den großen Freilandkasten gelassen, wo sie nach einigen Tagen ihre charakteristischen Gelege absetzten. Nahrung brauchen sie ebenso wenig wie die Ageniaspis. Die Schmarotzer, die 5-6 Tage später ausschlüpfen, als die Wirtstiere, grade zu der Zeit, wenn die Eiablage der Hyponomeuten begomen hat, wurden dann ebenfalls in den Freilandkasten ausgesetzt und stachen ohne weiteres die Gelege an.

Übrigens wurde die Zahl der zur Zucht verwendeten Falter einigermaßen beschränkt, um eine umso stärkere Infektion verhältnismäßig weniger Gelege herbeizuführen.

Indem nun beobachtet werden konnte, zu welcher Stunde und an welchem Tage gewisse Gelege sehr stark von Ageniaspis- 우 besucht worden waren - die Gelege wurden durch an den Zweig gebundene Zettelchen gezeichnet - war es möglich, eine Reihe von Entwicklungszuständen von bekamntem Alter zu erhalten. Freilich - durchaus genaue Daten können bei der Hyponomeuta naturgemäß nicht gewonnen werden, denn es dürfte sehr schwierig sein, bestimmte einzelne Eier eines Geleges von etwa 40 Eiern zu beobachten und zu merken. 
Die Daten verlieren auch an Wert dadurch, daß die wechselnde Witterung die Schnelligkeit der Entwicklung von Fall zu Fall beeinflussen wird; dann aber komnten auch unkontrollierbare Besuche von legenden Weibchen vor und nach dem gemerkten Zeitpunkte nicht verhindert werden.

Nach beendigter Flugzeit - Mitte August - wurde der Beobachtungskasten abgebrochen und ïber den Zweig ein großer, ausgesteifter Mullsack gebunden, so daß auch während des Winters bequem Material entnommen werden komnte.

Die zu konservierenden Gelege wurden vorsichtig mit einem Messer von der Rinde abgehoben, in einem Uhrglas mit heißem SublimatAlkohol-Eisessig übergossen und unter der Lupe angestochen; und zwar so, daß die Eihüllen möglichst an den Stellen durchstochen wurden, wo die linsenförmigen Eier mit ihren flachen Rändern aneinanderstoßen (Fig. 29); so konnte, ohne daß die Eier selbst wesentlich zerstört wurden, die Konservierungsfliissigkeit gut eindringen. - Formol-AlkoholEisessig gab hier weniger gute Resultate, wohl aber bei Konservierung der Räupchen und der folgenden Stadien. Die jüngsten Raupen lassen sich mit einem Pinsel bequem abnehmen, nachdem man behutsam die gemeinsame Schutzdecke ein Stïck abgehoben hat. Aus den großen Raupen wurden die Keimschläuche durch einfaches Zerreißen, wie es Bugnion beschreibt, freipräpariert. Das macht in einem Tropfen physiologischer Salzlösung auf dem Objektträger gar keine Schwierigkeit wegen des lockeren Zusammenhanges zwischen Wirt und Parasiten. In etwa $1 \mathrm{~cm}$ langen Raupen erkennt man die Schläuche schon mit bloßem Auge. Hier wurde übrigens auch mit dem schwachen Fuemungschen Gemisch konserviert. Die Imagines wurden zum Teil in Sublimat-, zum Teil ịn Formol-Alkohol-Eisessig konserviert (beide Lösungen stets warm verwendet). Ihre Chitinbekleidung ist so zart, daß es nicht nötig ist, die Tiere zu köpfen oder das Abdomen abzutrennen.

Alle Zustände der Ageniaspis, mit Ausmahme der Keimschläuche, wurden also imnerhalb ihres Wirtsgewebes liegend geschnitten; demn es wäre mir vermutlich ebensowenig, wie MARCHaL, der nach tagelangem Suchen ein Ei fand, gelungen, etwa durch Zerzupfen der HyponomeutaEier die Ageniaspis-Eier zu finden, noch viel weniger sie zu isolieren und zu orientieren. Zum Einbetten bediente ich mich ausschließlich der Nelkenöl-Collodium-Methode nach Hofmuans. Die Überführung der Objekte aus absolutem Alkohol in Nelkenöl geschah nach dem „Senkverfahren «, das man z. B. bei KaHLE (1908) beschrieben findet; ohne Schaden waren so in kiurzester Zeit selbst die stark chitinigen 
Gelege in reinem Nelkenöl. Ich ließ die Objekte einige Stunden in 48-grädigem und etwa eine halbe Stunde in 60-grädigem Paraffin.

Während die Imagines sich meist sehr leicht in 5 oder $10 \mu$ dicke Schnitte zerlegen ließen, mußte beim Schneiden der Gelege und der Raupen Mastix-Collodium angewendet werden. Hiervon wurden außerdem reichlich dicke Schnitte - 20-25 $\mu$ - angefertigt, um Totalpräparate der Ageniaspis-Stadien zu erhalten. Wenm man übrigens die Eier aus ihren Schalen herauspräpariert, lassen sie sich zwar besser schneiden, indessen ist das Überführen, die Orientierung und das Durchsuchen der Tafeln dann weit mühsamer, als das Bestreichen mit Mastix-Collodium, zumal wenn dies genügend mit durchaus wasserfreiem Äther verdünnt worden ist. Alle Schnitte sind mit Photoxylin zu überziehen, gạz besonders natürlich die dicken, die trotz des Überzuges sehr leicht fortschwimmen, wenn man sie beim Färben zu lange in absolutem Alkohol verweilen läßt.

Die-dicken Schnitte wurden gefärbt mit Borax-Carmin und Heidenhains Eisenhämatoxylin. Letztere Färbung läßt sich freilich nur an Schnitten durch solche Hyponomeuta-Eier mit Vorteil verwenden, in denen der Raupenembryo noch keine allzugroßen Fortschritte gemacht hat, etwa bis zur Versenkung des Keimstreifs; denn das dichte Embryonalgewebe bleibt so dunkel gefärbt, daß nur die im Eidotter gelegenen Ageniaspis-Eier erkennbar sind. Für die ïbrigen Schnitte verwandte ich in der Hauptsache Heidenhais, gern kombiniert mit Orange G oder vas Giesox (diese Kombination gibt vortreffliche Übersichtsbilder!), daneben Hämalaun; das Flemung-Material wurde mit Safranin gefärbt. Um eventuell die verschiedenen Chromatine durch die Färbung unterscheiden zu können, wurden Versuche mit Triazid nach MAYer und mit OBstscher Nucleolenfärbung (OBst 1899, Buchner 1909) gemacht, indessen ohne Erfolg.

\section{Entwicklungsgeschichtliches.}

\section{Das Ei im Ovarium.}

Der Nucleolus ist im rollständig entwickelten Vorei bereits rorhanden. Wir werden also, um seine Entstehung zu beobachten, noch weiter zurückgehen und das Ovarialei in seinem Wachstum studieren müssen. Dabei ergibt sich naturgemäß eine Untersuchung des weiblichen Geschlechtsapparates der Ageniaspis.

\section{Die Morphologie des weiblichen Geschlechtsapparates.}

Zur Ergänzung der wenig plastischen Vorstellung, die man an Schnitten gewinnt, sind Situspräparate der Geschlechtsorgane nötig. 
Die geringe Entwicklung des Fettkörpers und der Tracheen erleichtert das Präparieren, besonders wenn man in Alkohol gehärtetes Material verwendet.

Es haben sich nun die Angaben Bugnions über diesen Gegenstand als so zutreffend erwiesen, daß hier nur gauz kurz darauf eingegangen zu werden brancht:

Die umfangreichen Ovarien (ov) umfassen etwa haudförmig umbiegend den Mitteldarm und bestehen jederseits aus acht innig miteinander verbundenen Tuben. (Das beigegebene Schema Textfig. 1 soll nur die Organe in situ wiedergeben; im iibrigen sei auf die Abbildungen Bugnions verwiesen.) Ihrem breiten, hinteren Teil sitzt ein

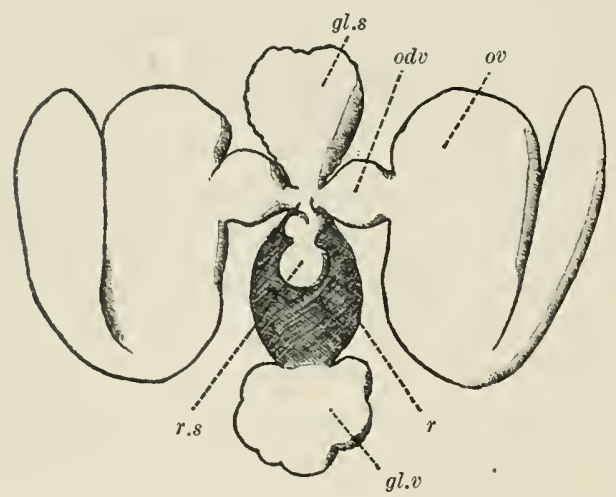

Textfig. 1. deutlich abgesetzter, kurzer Oviduct (ovd) an, durch ein außerordentlich hohes Epithel ausgezeichnet. Die Oviducte vereinigen sich zum Uterus, der rechtwinklig zu ihnen in dorsoventraler Richtung verläuft und an der Basis des Legestachels mündet.

Von der Vereinigungsstelle der Oviducte aus liegt kopfwärts als ein ansehnliches Gebilde die "glande sébacée« (BugNION) (gl.s), aus zwei in der Medianen innig verschmolzenen Blasen bestehend, die, was BugNIon nicht erkennen konnte, getrennt, wenn auch dicht nebeneinauder in den Anfangsteil des Uterus einmünden. Abdominalwärts davon ist das receptaculum seminis $(r . s)$ gelegen, ventral uach Art eines Flaschenbodens durch den Ausführgang eingestülpt. Bei befruchteten Exemplaren ist es erfüllt von Spermatozoenbündeln. Der Ausfiihrgang trägt eine kleine Erweiterung, eine Anhangsdrüse. Wir hätten also hier eine Ausnahme von der Angabe in Berleses Lehrbuch ( $I, 2$, S. 892), daß die Spermatotheca der Hymenopteren allgemein zwei Anhangsdriisen besitze.

Ventral vom receptaculum seminis liegt, sich weit nach hinten erstreckend, der »apparail sécréteur «, nach Bugnion das Homologon des Giftapparates der aculeaten Hymenopteren. (In der Fig. 52 Buc- 
NIoNs ist die natürliche Lage der Organe dadurch verändert, daß die Drüse samt ihrem Reservoir nach vorn geklappt ist, da sie sonst den Stachelapparat verdecken würde.) Wir unterscheiden, dem Uterus am nächsten, das sehr ansehnliche, schwach elliptische Reservoir (r), immer erfüllt von einem intensivst färbbaren Secret und die weiter hinten gelegene Drüse aus wenigen, sehr großen Zellen bestehend, die über die Oberfläche frei vorragen $(g l . v)$. Auch der Sammelgang ist mit Secret erfüllt. Von dem Reservoir dieser Drüse führt ein Gang nach dem Uterus, in diesem Gang jedoch habe ich das Secret nie beobachten können (Kontraktionen durch die Konservierung?).

Über die Funktion der eben beschriebenen Drïse können nur Vermutungen aufgestellt werden; Bugnion meint, daß ihr Secret zum Schlüpfrigmachen der Eier und der Legeröhre diene; bei andern nichtaculeaten Hymenopteren wird, wie mir Herr Dr. PAMPEL-Leipzig persönlich mitteilte, das Secret der der Giftdrüse der Aculeaten homologen Drüse zur mechanischen Beförderung der Eier bei der Ablage verwandt.

Zum »appareil sécréteur « rechnet Bugnion schließlich noch zwei »accessorische Drüsen«. Sie sind etwa von der Größe der Oviducte, liegen genau ventral von diesen und münden in den distalen Teil des Uterus. Besonders hervorheben möchte ich, daß sie dem Alter der Tiere nach verschieden ausgebildet zu sein scheinen: oft sah ich sie in frischgeschlüpften Tieren ein weites, von niederem Epithel bekileidetes Lumen besitzen, während in älteren Tieren durchweg das Epithel, nur noch an den peripher gelegenen Kernen kenntlich, kontinuierlich in das schaumige Secret übergeht.

\section{Der Bau der Ovarialtuben.}

Die Ovarialtuben sind, was man auf Schnitten deutlicher erkennt als am Totalpräparat, in ihrer Mitte derart umgebogen, daß das blinde »vordere «Ende kopfwärts liegt, die Mitte abdominal und der dem Eileiter zugerichtete 》hintere "Teil von der mittleren Umbiegung aus wieder nach dem Kopf zuläuft. Sie sind von dem sehr plötzlich sich verjüngenden Vorderende abgesehen bis zur Wachstumszone auffallend gleichmäßig dick.

Einen Endfaden vermochte ich zwar ebensowenig aufzufinden, wie Bugnion, wohl aber ist jede Tube in der üblichen Weise von einer sehr zarten peritonealen Hülle umgeben. Unter dieser wiederum liegt die von den Epithelzellen ausgeschiedene Tunica propria, die bei Anwendung der v. Gieson-Färbung als cin zarter roter Saum dentlich hervortritt ( $t . p$ der Fig. 1 z. B.). 
Was num die Zellelemente der Eiröhre selbst anbetrifft, so macht Bugnion folgende Angaben: ausgehend vom blinden Ende läßt er auf eine Keimzone eine Differenzierungszone folgen. Hier ordnen sich die Zellen zu einem länglichen Körper an, der sich mit einer Membran umgibt und einen Follikel repräsentiert. Dieser den Inhalt eines „Segmentes « darstellende Follikel wandert als Ganzes allmählich die Eiröhre hinab. Jeder Follikel besteht aus einer Lage undeutlich abgegrenzter peripherer Zellen, »cellules nutritives «, die eine das Keimbläschen enthaltende Masse einschließen: das in Bildung begriffene Ei. Der Follikel streckt sich immer mehr in die Länge, das breite hintere, dem Oviduct zugekelrrte Ende des Eies umgibt sich mit einem Chorion, während das vordere in das hier reichlicher entwickelte Follikelepithel überzugehen und von hier Nährstoffe zu beziehen scheint. Bugnion behauptet jedoch ausdrücklich, daß diese cellules mutritives das ganze Ei umgeben und daß keine besondern Nährzellen differenziert seien.

Vergleichen wir damit unsern Befund: die Keimzone erstreckt sich vom blinden Ende bis etwa zur halben Entfernung von der Unbiegungsstelle. Hier fand ich außer den Oogonien und Epithelzellen noch eine andre Art Zellen, über deren Deutung ich mir nicht klar geworden bin. Sie liegen regellos zwischen die Oogonien zerstreut, meist einzeln, bisweilen in Gruppen von zwei oder drei; sie sind etwa nur halb so groß wie diese und ganz besonders auffallend durch ihren intensiv färbbaren Kern. Bei Heidenhain-Färbung z. B. erscheint er meist tiefschwarz, bisweilen jedoch sieht er wie vacuolisiert aus. Das Plasma tritt gegen den Kern an Masse bedeutend zurück, oft ist es überhaupt nicht wahrzunehmen.

Auf die Keimzone folgt die Synapsiszone, die bis zur Umbiegung reicht. Sie enthält die für diese Zone charakteristischen Knäuelstadien; ein Schwund der Zellgrenzen hingegen war nicht in der von andern Insekten her bekannten Weise zu konstatieren.

Weiter hinten, in der Nähe der Umbiegung sehen wir dann eine durch ihre unten zu besprechende Kernstruktur ausgezeichnete Zelle, die Eizelle, aus der vor ihr gelegenen Zellgruppe heraustreten - die Differenzierungszone. Die Eizelle umgibt sich mit einem kompakten Epithel und wir erhalten die Eikammer; die davor liegenden Zellen bilden, von wenigen Epithelzellen begleitet, die Nährkammer. So gestaltet sich entgegen der Angabe Bugnions im Prinzip die für die Hymenopterenovarien charakteristische Abwechslung von Ei- und Nährkammern; nur sind die Einschniirungen dazwischen ganz unbe- 
deutend (bei einer verwandten Pteromalus-Art traf ich viel typischere Verhältnisse an).

Die Nährzellen - ich glaube sieben zu zählen - haben relativ große, runde Kierne; diese sind nie in der für andre Insekten, etwa für die Honigbiene (Paulcke 1901) beschriebenen Weise gelappt, wohl aber zeigen die dem Ei zunächst liegenden Zellen durch ihre Verkleinerung und durch die Verklumpung ihrer Kerne an, daß sie in Beziehung zum Ei getreten sind (Fig. 4).

Daß die Eiröhren so glatt verstreichen, wird verständlich bei Betrachtung der Wachstumszone, die die 2. Hälfte der Tube einnimmt; denn hier treffen wir allerdings die von Bugnion in ihrer prinzipiellen Bedeutung crkannten Verhältnisse an: bald nach der Umbiegungsstelle sehen wir die einzelnen Eifollikel mit ihren Nährzellen nicht mehr hintereinander angeordnet, wir finden vielmehr eine Nebeneinanderordnung und je weiter wir nach dem Oviduct zu gehen, umsomehr stauen sie sich an. Am besten erkenmen wir dies wegen der Zartheit der peritonealen Hülle am quergeschnittenen Ovarium (Fig. 15): in verschiedener Höhe getroffene Follikel sind von einer gemeinsamen Hülle umschlossen. Diese Anstauung bedingt natürlich eine entsprechende Erweiterung der Ovarialtube.

Die histologischen Zustände der Wachstumszone sollen gesondert besprochen werden im Zusammenhange mit den Veränderungen am wachsenden Ei. Wir schließen daher sogleich die Bemerkung an, daß sich die erwachsenen Eier oft noch von einem Rest von Follikelepithel umkleidet vor dem Oviduct ansammeln, und wir können diesen Teil der Eiröhre als Calyx bezeichnen. Bugnion bringt, da ihm die wahre Entstehung der Embryonenketten unbekannt war, diese Anhänfung legereifer Eier in Zusammenhang mit der Anzahl der Larven.

Wir haben also bei Ageniaspis eine Art dieroistischer Ovarien vor uns, wie wir sie etwa von Culiciden und gewissen Braconiden kennen, insofern wir auch hier freie Follikel beobachten; nur ist bei Ageniaspis nicht jedes Orarium ein einheitlicher Sack, wie bei der Braconide Aphidius z. B. (Berleses Lehrbuch, Fig. 1193), mit diffus darin verteilten Follikeln, sondern es sind, wie wir sehen, acht solche Säcke als eine Kombination von typischen polytrophen und dieroistischen Ovarien miteinander vereinigt.

\section{Das wachsende Ei.}

Im wachsenden Ovarialei findet nach den Angaben Silvestris die Trennung des Nucleolıs vom Keimbläschen statt, und zwar schon in 
der "geschwärzten «, d. h. zum Auskriechen bereiten Puppe, so daß im frisch geschlüpften Tier der größte Teil der Eier bereits vollständig entwickelt ist: am vorderen Pol liegt der Eikern, "presenta sotto forma di tre o quattro masse di cromatina compatte «, am hinteren Pol liegt der Nucleolus. Aber »in uno stato di sviluppo antecedente, l'ovo ovarico ha una vescicola germinativa con una membrana e reticulo cromatinico ben distinto; in uno stato intermedio non si vede più la membrana e la cromatina si è addensata a formare circa dieci cromosomi, che poi finiscono per confondersi a poco fra di loro, fino a costituire il corpo nucleare cromatinico dell' oocite di primo ordine $\ll$.

In welchem Znsammenhang num etwa diese Auflösung des Kermes mit dem Auftreten des Nucleolus steht oder wann er überhaupt sich zum erstenmal zeigt, ist aus den Angaben Silvestris nicht zu entnehmen (Figuren sind nicht beigegeben).

Ich verfolgte daher die Oocyte von ihrem ersten Auftreten an bis zur Ablage und bin zu Ergebnissen gelangt, die Silvestris Beobachtungen zu ergänzen vermögen. Die parallelen Veränderungen der Nähr- und Epithelzellen sollen gleichzeitig geschildert werden.

Die jüngsten Oocyten zeichnen sich, wie schon angedentet, vor den Nährzellen durch die auffällige Gestaltung ihres Kernes aus (Fig. 1). Dieser erscheint als ein heller Fleck; an einem Pol aber hat sich das Chromatin in sehr charakteristischer Weise (»flatschig «) angehäuft. In den meisten Fällen ist es der hintere Pol, bisweilen aber findet sich die Anhänfung seitlich oder vorn. Im übrigen gleicht die junge Eizelle den Nährzellen $(n z)$; höchstens wäre noch ihre manchmal unregelmäßige Gestalt hervorzuheben, die vielleicht auf eine gewisse Beweglichkeit, zum mindesten Plastizität hindeuten könnte; denn die Eizelle beginnt ja jetzt erst aus dem Verband der Nährzellen herauszutreten. Die Epithelzellen (epz) sind nur in ganz geringer Menge entwickelt. Ihre Kerne zeigen durchaus eine gleichmäßige Granulierung. Sie vermehren sich indessen sehr schnell und umgeben dann die Eizelle.

Diese ist zunächst von runder Gestalt (Fig. 1), bald aber beginnt sie sich lebhaft zu strecken; dabei werden die Konturen sehr charakteristisch unregelmäßig (Fig. 2, hier auch eine sich teilende Epithelzelle); im vorderen Teil liegt der Kern und er behält diese Lage von nun an immer bei. Von irgendwelchen andern Zelleinschlïssen bemerken wir keine Spur.

Das nächste, scharf isolierbare Stadium bringt folgende Veränderungen (Fig. 3 jüngeres, Fig. 4 älteres Ei dieses Stadiums): die Nährkammer, deren Zellen gelegentlich direkt in Beziehung zu der Eizelle 
treten (Fig. 4), hat sich deutlich von der Eikammer gesondert; deren Epithel flacht sich mehr und mehr ab und umschließt das Hinterende des Eies vollständig. Seine unregelmäßigen Konturen haben sich ausgeglichen, wir haben ein elliptisches Gebilde vor uns, die älteren Eier dieser Entwicklungsperiode zeigen bereits eine schwache Einschnürung in der Mitte.

Weit bedeutungsvoller aber sind die Wandlungen des Eikerns: die polare Chromatinanhäufung sehen wir schwinden und beobachten eine gleichmäßige Verteilung der chromatischen Masse im Kernraum; aber von dieser Verteilung abgesehen, gewinnt man den Eindruck, daß sich auch die Menge des Chromatins verringert hat.

Das Plasma des hinteren Eiteiles dagegen ist erfüllt von durch Eisenhämatoxylin geschwärzten Granulationen, die nach dem Hinterende zu immer dichter liegen und unter denen sich ab und zu eine oder mehrere größere Verdichtungen finden.

Weiterhin aber gewahren wir einen kleinen dunklen Körper $(n l s)$. Seine Lage am hinteren Ende des Eies ist nicht so genau fixiert, wie die des Kernes am Vorderende. Er nimmt bald an Größe zu und wir erkennen, daß er aus mehreren kleineren Körpern zusammengesetzt ist. Das weitere Schicksal dieses Gebildes läßt keinen Zweifel darüber, daß es der Nucleolus ist, der hier zum erstenmal uns entgegentritt!

Es sei hervorgehoben, daß auf diesem Entwicklungszustand der Oocyte von einer Kernauflösung nichts zu bemerken ist.

Diese setzt erst im nächsten, von Silvestri als 》mittleres « erwähnten Stadium ein, das ich unmittelbar an das vorhergehende anschließen muß, da vermittelnde Stadien nicht gefunden werden konnten. Jetzt findet nun auch die oben geschilderte Loslösung des gesamten Follikels statt, ohne daß damit wesentliche histologische Veränderungen innerhalb des Follikels in Zusammenhang stïnden. So finden wir denn die Nähr- und Epithelzellen hier in derselben Ausbildung wieder, wie im vorigen Stadium. Das Ei selbst hat sich noch weiter gestreckt und die Einengung in der Mitte läßt Vorder- und Hinterende kolbig hervortreten (Fig. 5).

Der Eikern aber zeigt folgendes Bild: in einem hellen Hof, der an Umfang und Lage dem Keimbläschen entspricht, liegen kurze, intensiv färbbare Stäbchen. Sie sind vorwiegend peripher gelegen, ohne aber eine ganz bestimmte Anordnung erkennen zu lassen. Über ihre Zahl konnte ich mir keine völlige Klarheit verschaffen, ich zällte acht bis zehn, was mit Silvestris Angaben ungefähr iibereinstimmt. 
Mit dieser Kernauflösung hat, das wurde schon gesagt, die Entstehung des Nucleolus zunächst nichts zu tun, wohl aber konstatieren wir, daß er an Umfang zugenommen hat.

Die folgenden Follikel sind dadurch bemerkenswert, daß die Nährkanmern mehr und mehr zurücktreten, indem entsprechend dem rapiden Wachstum des Eies die Nährzellen sehr lebhaft resorbiert werden (Fig. 8). Der Mittelteil des Eies, der Eihals, beginnt sich zu krümmen, (so etwa wie es in der Fig. 7 dargestellt ist), das Hinterende gewinnt dem Vorderende gegenüber an Umfang, hier beginnt sich auch das Clorion auszubilden $(c h)$.

Im Kern beginnen jetzt die peripheren Chromatinpartikel nach dem Centrum zu rücken (Fig. 6) und sich der Längsachse des Eies parallel anzuordnen (Fig. 7). Auf einer besonders gut gelungenen Schnittserie sah ich auch stets ein deutliches Fadengerüst auftreten, das ganz nach Art einer Teilungsspindel einen richtenden Einfluß auf die chromatischen Elemente auszuüben scheint. Gleichzeitig aber scheinen sich die einzelnen Körperchen zu vereinigen, zu längeren Stäbchen zusammenzufließen (»... che poi finiscono per confondersi a poco fra di loro Silvestri) und wir erhalten dann Bilder, wo neben den schon ausgebildeten, glatten, schlanken Chromosomen, wenn es gestattet ist, diese Bezeichnung zu gebrauchen, Gebilde gelegen sind, die durch Einschnürungen etwa ihre Entstehung aus verschmelzenden Elementen wahrscheinlich machen. Fig. 8 gibt ein solches Zwischenstadium wieder.

In dieser Kernfigur bemerkt man nun aber außer den soeben geschilderten Chromatinkörpern noch kleinere, andersgeartete Partikelchen $(x)$ : zuerst, wenig lokalisiert, an der Peripherie des sich ordnenden Haufens sichtbar, nehmen sie bald, indem sie sich von ihrem Entstehungsort entfernen, mehr polare Stellungen ein. In den Figuren 6-8 können wir diese Vorgänge verfolgen. Bei Siluvestri finden wir die beschriebenen Gebilde nicht erwähnt. Ich werde sie im Folgenden als »abgestoßenes Chromatin « bezeichnen.

Wenn dann die Nährkammer völlig verschwunden ist und auch ans vorderen Eipol sich das Chorion auszubilden beginnt, hat auch die Ordnung und Ausbildung der Chromosomen ihren Abschluß erreicht: sie liegen in einem hellen, länglichen Hof im Vorderteil des Eies, zueimander und zur Längsachse des Eies parallel (Textfig. 2).

Dieses Stadium des Kernes liegt ganz offenbar der Beschreibung und den Abbildungen zugrunde, die Silvestri von dem »ovo ovarico a completo sviluppo «ibt. Wir werden aber finden, daß eimmal die Entwicklung des Kernes hiermit noch nicht eigentlich beendet ist, 
und daß anderseits die Eiform, wie sie von Silvestri abgebildet wird, einem älteren Kernstadium entspricht. Vor allem aber, von dem relativen Alter ganz abgesehen, vermàg ich der Schilderung, die SilvestrI von diesem Kernstadium gibt, nicht zuzustimmen: es sollen nämlich drei oder vier einfache Chromatinstäbchen vorhanden sein.

Bei schwächerer Vergrößerung glaubt man dem auch deutlich vier wahrzunehmen; auch bei stärkerer Vergrößerung traf ich sehr häufig (bei günstiger Orientierung des Präparates?) auf eine Ebene, in der die gleiche Zahl von Stäbchen lag; beim Fokusieren jedoch und noch besser auf Querschnitten zählte man mehr als vier, es können acht bis zehn sein. Da die Vierzahl sich beim Studium dieser Kerne mit solcher Deutlichkeit bemerkbar macht, und wir auch späterhin bei der Reifung vier Chromosomen beobachten werden, so ist es wohl möglich, daß wir hier in Wirklichkeit Schleifen vor uns haben und nicht einfache Stäbchen.

Vor und hinter dieser charakteristischen Kernfigur liegt das »abgestoßene Chromatin«; es sind nur wenige kleine Körnchen, bisweilen sogar nur eines (sie werden späterhin vollständig resorbiert). Ihre starke Färbbarkeit läßt sie aber immer sehr deutlich werden.

Das Hinterende des Eies zeigt den Nucleolus; er erscheint bereits mehr als ein einheitliches, wenn auch nicht homogenes Gebilde. Die ihn ursprünglich zusammen-

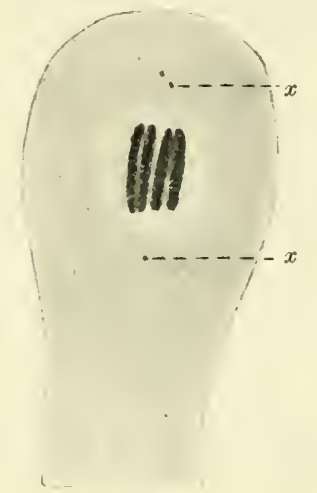

Textfig. 2.

Vorderer Pol eines Ovarialeies: die (4) Chromosomen des Eikerns parallel. $x$, `abgestoßenes Chromatine. setzenden Einzelkörper lassen sich nicht mehr gesondert unterscheiden (Fig. 9). Auf Silvestris Darstellung des Nucleolus werden wir beim reifen Ei zu sprechen kommen.

Dic Granulationen sind noch erhalten, und als eine Neuerscheinung bemerken wir an unbestimmten Stellen Vacuolen $(v)$.

Endlich, in den letzten Entwicklungsstadien erfährt vor allem die Gestalt des Eies noch weitere Umbildungen: der Halsteil wird schlanker und gewundener; die Follikelzellen schmiegen sich in eigentümlicher Weise in die Windungren ein (der in Fig. 9 dargestellte Längsschnitt mag eine umständliche Beschreibung überflïssig machen). Entsprechend der Halsausbildung heben sich Vorder- und Hinterende des Eies schärfer keulenförmig ab. Der Vorderpol hat sich abgeplattet. 
Hier sowohl, wie an dem verhältnismäßig viel umfangreicheren Hinterende ist das Chorion viel stärker ausgebildet als am Halsteil.

Aber auch der Kern verändert sich weiter: indem der helle Hof undeutlicher wird, rücken die bisher getrennten Stäbchen aneinander; wir sehen an den Polen deutlich ihre Enden vorragen.

Das abgestoßene Chromatin hat seine Lage beibehalten.

Der Nucleolus hat nun etwa seine definitive Größe erreicht, er erscheint einheitlich; seine inneren Partien, bisweilen auch der ganze Körper, sind oft heller gefärbt als die peripheren und sehr häufig ist er vacuolisiert.

Die vollständig entwickelten Eier, wie sie sich im Calyx ansammeln, zeigen dann folgende Beschaffenheit: Vorder- und Hinterteil sind einander genähert dadurch, daß der Eihals durch den Druck der sich ausammendrängenden Eier, wie Bugnion wohl mit Recht vermutet, zusammengestaucht worden ist (Fig. 10). Vom Follikelepithel sind häufig noch Reste vorhanden, namentlich in den Falten des Halsteils. Der vordere Teil zeigt eine Eindellung, die auch Silvestri abbildet. An deren Grund liegt die von der Seite als ein heller, länglicher Fleck erscheinende Mikropyle $(m)$ (von der MarchaL sagt, daß er sie im Gegensatz zu Bugnion nie habe erkennen können).

Der Eikem, der von Bugnion und Marchal überhaupt ïbersehen und von Silvestri nicht in dieser definitiven Ausbildung beobachtet worden ist, ist zu einem länglichen, kompakten, homogenen Körper geworden; auch Querschnitte lassen keine Spur der einzelnen Stäbchen mehr erkennen. Sein heller Hof ist geschwunden.

Davor und dahinter findet sich wieder das »abgestoßene Chromatin «.

Der hintere Teil zeigt die einzige Veränderung gegen die früheren Stadien (mit Ausnahme der vorhergehenden), daß die Granulationen sich nicht mehr nachweisen lassen; sie sind offenbar resorbiert worden.

Was Bugnion sowohl wie Marchal für den Eikern gehalten haben. ist. worauf auch Silvestri aufmerksam macht, in Wirklichkeit der Nucleolus.

Ich habe iiberdies wiederholt Eier in den Ovidukten angetroffen und Kern und Nucleolus in dem zuletzt beschriebenen Zustand gefunden. Nur die Form der Eier ist eine andre: das rorangleitende Hinterende ist zugespitzt und verdünnt, der Hals, ja das ganze Ei zieht sich aus, - Veränderungen, die bei der Enge der Oviducte ohne weiteres verständlich sind. 
Zur Entwicklungsgesch. des polyembryonalen Chalcidiers Ageniaspis usw. 435

Anhang: Zusammenfassung der Vorgänge innerhalb deswach senden Eies.

Es dürfte sich empfehlen, die Vorgänge in der Oocyte selbst au; dem Zusammenhang, in dem sie soeben dargestellt wurden, herauszuheben und gesondert nochmals zu betrachten.

Vom Kern ausgehend können wir folgende Perioden unterscheiden:

I. Vor der Auflösung des Kerns

a) polare Chromatinanhäufung (Fig. 1, 2)

b) die polare Chromatinanhäufung schwindet; gleichmäßige Verteilung der chromatischen Substanz im Kern - in der hintern Partie des Eies treten 1. Granulationen auf und 2. der Nucleolus, aus mehreren einzehen Körnern bestehend (Fig. 3, 4).

II. Auflösung des Kerns.

Der Kern erscheint als ein heller Hof. Hinten Granulationen und Nucleolus.

a) Im Kern zahlreiche, periphere kurze und dicke Körper. (Fig. 5.)

b) Die Körper rücken nach dem Centrum, ordnen sich parallel der Eilängsachse (Fadengerüst) und vereinigen sich zu (wahrseheinlich 4) „Chromosomen «. - Chromatinkörnchen an beiden Enden der Kernfigur, die zum erstenmal zu Beginn des Ordnungsprozesses beobachtet wurden. - Der Nucleolus wird zu einem einheitlichen Gebilde und beendet sein Wachstum (Fig. 6-8, Textfig. 2).

III. Nach der Auflösung des Kerns.

Das Ei hat seine maximale Größe erreicht, die Nährkammer ist geschwunden. - Die 》Chromosomen « vereinigen sich zu einem kompakten Gebilde, der helle Hof schwindet - vor und hinter diesem liegt das »abgestoßene Chromatin «. - Die Granulationen schwinden, der Nucleolus bleibt erhalten (Fig. 9, 10).

Wir sehen zunächst neben dem Kern dreierlei Gebilde im Plasma der Oocyte auftreten:

1. Die Granulationen in der hinteren Eihälfte, 2. den Nueleolus, 3. das "abgestoßene Chromatin «.

Unser Interesse gilt besonders dem Nucleolus und es fragt sich, welche Schlüsse über seine Herkunft und seine Natur wir aus den Beobachtungen ziehen können. Wir vermögen zugunsten der von SiLvestri behaupteten Herkunft des Nucleolus aus dem Keimbläschen nur anzuführen, daß sein erstes Auftreten nnd sein erstes Wachstum mit dem Versehwinden der polaren Chromatinanhäufung in Kern zu- 
sammenfällt. Dasselbe gilt aber auch von den Granulationen. Diese freilich könnten wohl eher als Produkt der aufgenommenen Nährzellmasse betrachtet werden; dafür spricht ihre baldige Resorption im Eiplasma und dann die allerdings nur an einem Tier gemachte Beobachtung, daß sie zur Zeit ihres ersten Auftretens über das gesamte Plasina, auch am vordern Pol verteilt sein können.

Gegen Silvestris Angabe könnte geltend gemacht werden, daß wir den jungen Nucleolus nie in der Nähe des Kernes liegen sahen, sondern von Anfang an in seiner definitiven Lage im hintern Ende des Eies. Bei seiner anfänglichen Kleinheit freilich kam er auch leicht, falls er wirklich eimmal dem Kern benachbarter lag, unter den Granulationen ïbersehen worden sein. Jedenfalls wurde der Nucleolus in keiner der Modifikationen, in denen wir ihn im Plasma finden, im Kern oder in den Nährzellen vorher gefunden.

So geschieht denn auch seine Bildung nicht in einem Akt, sondern er wächst allmählich heran und verändert gleichzeitig sein Aussehen. Und zwar hat er sein Wachstum noch nicht abgeschlossen, wenn die vorhin mit seiner Entstehung in Bezielıung gebrachte polare Chromatinanhäufung aus dem Kern verschwunden ist; dies scheint vielmehr erst nach der Auflösung des Kernes der Fall zu sein. Zur selben Zeit ungefähr sind aber auch alle Nährzellen in das Ei aufgenommen worden.

So können weder ïber die Herkunft noch ïber die Größenzunahme des Nucleolus eindentige Angaben gemacht werden.

\section{Das Ei im Hyponomeuta-Ei.}

Hier sollen uns zunächst die morphologischen Veränderungen beschäftigen, die das Ei von seiner Ablage im Juli bis zum AbschIuß der Embryonalentwicklung seines Wirtes, Ende August, erleidet.

\section{Das Vorei.}

Ein frisch abgelegtes Ei mit noch ruhendem Kern zu finden ist mir nicht geglückt. Nach Silvestri behält das eben abgelegte Ei nur für sehr kurze Zeit die »Flaschenform《 und wird birnenförmig; wir sahen aber, daß diese Form bereits durch den Legevorgang, ja schon durch die Anstaumng im Calyx verloren gegangen ist. Und ich möchte bezweifeln, ob wirklich die alte Flaschenform nach der Ablage noch einmal auftritt.

Der Kern besteht nach Silvestri aus einer morulaartigen, runden bis schwach ovalen, dichten Anhäufung von Chromatinkörnern. In seiner Fig. 1 aber bildet ihn SiLvestri als einen homogen erscheinenden Kör- 
per ab. Ich bin geneigt, in dem von Silvestri abgebildeten Kern den von uns im legreifen Ovarialei beobachteten wiederzufinden, der uns als ein kompakter Körper erschien.

Der Nucleolus gleicht nach Silvestri dem des Ovarialeies.

\section{Die Reifung.}

Der Schilderung der eigentlichen Reifungsvorgänge möchte ich vorausschicken, daß ich ebensowenig wie SiLvestrI einen Unterschied in der Entwicklung zwischen dem befruchteten und dem unbefruchteten Ei nachweisen komnte. (Daher reiht sich die Fig. 13, die ein befruchtetes Ei darstellt, ohne weiteres in den Cyclus der ïbrigen Eier ein.)

Über Form und Hüllen der Eier kann hier gleich folgendes für diese Periode allgemeinguiltiges gesagt werden: die Gestalt ist länglich und wechselt zwischen elliptisch, oval und birnförmig, wie sie auch Silvestri beschreibt. Oft erkennen wir noch am vorderen Pol einen schwanzartigen Anhang, selten gestreckt, meist verkrümmt und vom eigentlichen Ei durch Einbuchtungen abgeschnürt. Dieser "Eistiel « entsteht wahrscheinlich bei der Ablage des Eies; denn er liegt an dem Pol, der zuletzt den Oviduct und den Legebohrer passiert und deshalb unter dem Druck dieser Organe - das ganze Ei ist ja sehr plastisch in eine Spitze ausgezogen wird (Fig. 11, 12, 16).

Ein Chorion ist wohl noch vorhanden, aber so zart, daß es meistens nicht sichtbar ist; bisweilen freilich tritt es deutlich hervor, so namentlich an Stellen, wo das Eisplasma ein wenig bei der Konservierung zurückgetreten ist (Fig. 14ch).

Eine membrana vitellina dagegen ließ sich nicht feststellen.

Ferner vermissen wir durchweg das »abgestoßene Chromatin «, das im Ovarialei bis zuletzt den Kern begleitete. (Vielleicht findet es sich noch neben dem ruhenden Kern des bereits abgelegten Eies?)

Die Vorgänge der Reifung setzen jedenfalls sehr bald nach der Ablage ein, höchstens 10-15 Minuten danach; denn mehr Zeit verging nie bis zur vollständigen Konservierung des frisch infizierten Geleges und abgelegte Oocyten 1. Ordnung wurden ja niemals beobachtet.

Die 1. Reifungsteilung. Die jüngsten der mir zur Verfügung stehenden Stadien der 1. Reifungsteilung zeigen den Kern bereits in Anaphase; die Teilungsebene liegt merkwürdigerweise (in Bestätigung der Beobachtung Silvestris) nicht genau rechtwinklig zur Längsachse des Eies. Fig. 11 zeigt die völlige Trennung und das Auseinander- 
rïcken der chromatischen Elemente der Tochterkerne; der nächste Schritt ist die Konzentration der Tochterchromosomen (Fig. 12).

Während dieser Teilungsvorgänge ließ sich zuweilen mit aller Deutlichkeit die Zahl der Chromosomen, über die Silvestri nichts Bestimmtes aussagt, ermitteln: ich habe vier zählen können.

Der Nucleolus $(n l s)$ nimmt währenddessen eine nicht näher charakterisierbare Lage im hinteren Teil des Eies ein und scheint keinerlei Beziehungen zu den Vorgängen am Eikern aufzuweisen.

Die 2. Reifungsteilung. Die beiden Kerne, deren Entstehung wir eben verfolgten, der 1. Richtungskörper und der Kern der Oocyte 2. Ordnung gehen direkt zu neuen Teilungen über. So zeigt uns z. B. Fig. 13 zwei Teilungsfiguren, beide auf dem Stadium der Anaphase, und zwar liegt im vorderen Teil des Eies — der » parte polare «SILvESTRIs die karyokinetische Figur des 1. Richtungskörpers $\left(p_{1}\right)$, während im hintern Teil, doch immer mehr nach der Eimitte zu, im »parte embrionale «Sinvestris die Bildung des 2. Richtungskörpers sich vollzieht $\left(o_{2}\right)$. (Der schwarze Körper $(s p)$ neben der hintern Kernfigur ist das Spermatozoon.) Die beiden Teilungen verlaufen hier ungefähr in derselben Ebene, wie die 1. Reifungsteilung.

So gleichzeitig jedoch, wie es nach diesem Bild scheinen könnte, verlaufen die beiden Teilungen nicht immer. So fanden sich einige Präparate (Fig. 14), aus denen hervorzugehen scheint, daß die Teilung des 1. Richtungskörpers $\left(p_{1}\right)$ der 2. Reifungsteilung $\left(o_{2}\right)$ vorausgeht. Gleichzeitig beobachten wir hier, daß die Ebene der Richtungsverteilungkörper ungefähr rechtwinklig steht zu der der 1. Reifungsteilung. Viel Wert möchte ich indessen diesem seltenen und aberranten Vorkommen nicht beilegen.

Denn viel häufiger wurden Eier gefunden, wo das zeitliche Verhältnis der beiden Teilungen umgekehrt ist (Fig. 16: der 2. Richtungskörper ist gebildet $\left(p_{2}\right)$, der Eikern in den ruhenden Zustand getreten $\left(o_{3}\right)$, während der 1. Richtungskörper $\left(p_{1}\right)$ sich noch in Teilung befindet, die Teilungsebene wie im letzten Fall gelegen.

Silvestri erwähnt nichts von einer zeitlichen Differenz der Teilungen, und mein Material grade von diesen Stadien erlaubt zwar, wenn auch die wenigen Präparate recht klar sind, keine statistische Entscheidung, welcher Fall der typische ist, jedoch im Hinblick auf die Verhältnisse am reifen Ei (s. unten) möchte ich der Ansicht zuneigen, daß der letzte Modus - 2. Reifungsteilung eher vollendet, als die Teilung des 1. Richtungskörpers - als der normale zu betrachten ist. 
Die Zahl der Chromosomen ließ sich hier mit völliger Sicherheit nur einmal feststellen: in dem der Fig. 16 zugrunde liegenden Präparate zeigte die eine Hälfte der Teilungsfigur des 1. Richtungskörpers wiederum vier Chromosomen (der Wirrwarr der Fig. 14 allerdings scheint kompliziertere Verhältnisse anzudeuten).

Wir können aber auch in bezug auf die Lagerung der Richtungskörper, bzw. der Mitosen Verhältnisse konstatieren, die von den Beobachtungen Silvestris (und auch von denen andrer Autoren, z. B. DonCASTER (1906) an Tenthrediniden) abweichen. Ein Blick auf Fig. 16 zeigt uns folgendes: der 2. Richtungskörper $\left(p_{2}\right)$ liegt am vordern Pol, der Eikern (nummehr weiblicher Vorkern) nach dem hintern Pol zn $\left(o_{3}\right)$ und in der Eimitte zwischen den beiden Kernen ist die Teilungsfigur des 1. Richtungskörpers $\left(p_{1}\right)$ gelegen. Grade diese Lagerungsverhältnisse sind wiederholt deutlich zu erkennen gewesen, sehr sehön namentlich an aufrechtstehenden, d. h. zufällig rechtwinklig zur Schnittebene orientierten Eiern (Vorteil der dicken Schnitte!).

Weiterhin tritt normalerweise in den Eiern dieses Stadiums eine offenbare Differenzierung des Eiplasmas auf, mit der wir es beim reifen Ei ausfïhrlicher zu tun haben werden.

Vom Nucleolus gilt dasselbe, was bei der 1. Reifungsteilung iiber ihn gesagt wurde.

Das reife Ei. In vier Stunden etwa ist die Reifung vollendet und es ist nummehr das reife Ei zu beschreiben (Fig. 17).

Sein Plasma zunächst ist im typischen Falle ausgezeichnet durch die eben erwähnte Differenzierung, die, wie ich hinzufügen will, zwar nie vor der 2. Reifungsteilung und der Teilung des 1. Richtungskörpers beobachtet wird, oft aber auch auf späteren Stadien erst erscheint. Und zwar färbt sich der vordere Pol des Eies hell, der hintere dagegen dunkel; bei Borax-Carminfärbung tritt der Unterschied besonders schön hervor. Die helle Färbung des vorderen »Polar «-Teils (Silvestri) erstreckt sich nur über eine geringere Menge des Eiplasmas, ein Viertel oder meist etwa ein Drittel. Die Begrenzung des Polarteils gegen den „Embryonal «-Teil (Silvestri) sah ich kaum so seharf, wie es die $\mathrm{Ab}$ bildungren SiLvESTR Is zeigen, vielmehr einen sehr zarten und allmählichen Übergang. Ferner weichen meine Beobachtungen von denen Silvestris insofern ab, als die Grenze beider Plasmateile keine Grade ist, vielmehr erseheint der Polarteil konvex, so daßs der Embryonalteil sich an der Eiperipherie weiter nach vorn erstreckt. Später dominiert ja, wie sich zeigen wird, der Polarteil ïber den dunklen Teil des Eies an Ausdehnung und Masse. 
Die Struktur des Plasmas ist sehr zart wabig, fast homogen erscheinend (die mit Bleistift hergestellten Abbildungen geben ungewollt diese Struktur gut wieder), jedenfalls sozusagen 》rein plasmatisch «, demn von Dottereinlagerungen war nie eine Spur nachzuweisen. $\mathrm{Ab}$ und zu zeigen sich Vacuolen, doch weit seltener als im Ovarialei.

Wenden wir uns jetzt den wichtigeren Bestandteilen des reifen Eies zu, so ist unter den im Embryonalplasma gelegenen in erster Linie der Eikern $\left(o_{3}\right)$ zu erwähnen: er ist von beträchtlicher Größe, insofern sein Durchmesser etwa halb so groß sein mag, als das Ei selbst breit ist. Er liegt nie median, vielmehr immer der Eiperipherie ein wenig genähert. Bei jeder Färbung zeichnet er sich durch seine außerordentliche Zartheit aus — bei einem zufällig stark überfärbten Heidenhain-Präparat hob er sich ganz außerordentlich scharf von dem dunklen Plasma ab; sonst erscheint er als ein nur wenig Differenzierungen aufweisender, heller Fleck, außen durch einen wenig dichten Ring von Körnchen begrenzt; im Innern zeigen sich spärliche Chromatinkörnchen auf einem zarten Gerüstwerk.

Neben dem Eikern, ebenfalls im dunklen Embryonalteil, begegnen wir wieder dem Nucleolus $(n l s)$, dessen Heranwachsen und verschiedene Znstände im Ovarialei wir schon kennen gelernt hatten. Hier jedoch, wie überhanpt in den reifenden Eiern scheint er in mancher Beziehung labiler zu sein, labiler auch, als Silvestri ihn darstellt. So wird vielleicht eine genanere Schilderung seines Verhaltens am Platze sein.

Silvestri sagt nämlich vom Nucleolus, daß er während der Reifungsvorgänge weder Gestalt noch Form ändre, sondern dieselbe Ausbildung wie im vollständig entwickelten (im Sinne Silvestris) Ovarialei beibehalte. Und von diesem heißt es: »il nucleolo... se è colorito molto intensamente, appare di una tinta uniforme«, bei schwacher Färbung jedoch und bei genügender Differenzierung nach Eisenhämatoxylin zeige er 》delle piccole masse colla caratteristica colorazione nera, mentre il resto l'ha già perduto «. Die Abbildungen - auch die als Illustration für den letzten Fall gegebene Textfig. 3! — zeigen immer einen homogenen schwarzen Klumpen und es erhellt nicht, wo die bei gewisser Differenzierung schwarz bleibenden »masse « liegen.

Über seine Lage zunächst läßt sich für das reife Ei nichts bestimmtes aussagen: bald liegt er nahe dem Kern, bald davon entfernt, bald mehr central, bald peripher. Er ist wesentlich kleiner als der Eikern und von ziemlich konstanter Größe.

Seine Gestalt und Struktur zeigen nun aber recht verschiedene 
Modifikationen. Zur Beurteilung der Befunde möchte ich zuvor auf die Schwierigkeiten aufmerksam machen, die der Beobachtung in Wege stehen und sich aus der Natur des Materials ergeben: jedes Ei, wemn es nicht grade sehr günstig liegt, muß durch den umhüllenden Hyponomeuta-Eidotter, der immer zart mitgefärbt ist, hindurch betrachtet werden.

So wird der Nucleolus beobachtet als ein zartes, duftiges Gebilde, das sich nur wenig von dem umgebenden Eiplasma abhebt, homogen, von unregelmäßiger amöboider Gestalt, so daß das Ganze etwa dem Plasmahof einer Furchungszelle eines dotterreichen Eies gleicht (Fig. 13) - oder aber er kann bei sonst gleichen Eigenschaften auch abgerundet sein (Fig. 11, 17) und in diesem Fall auch Vacuolen besitzen (Fig. 12).

Diese abgerundete, zarte und vacuolisierte Form kennen wir schon rom erwachsenen Ovarialei her; sie ist auch für das reifende Ei sehr charakteristisch; die merkwürdige amöboide Form dagegen ist neu.

Drittens aber - ein selteneres, aber wohlcharakterisiertes Vorkommen - kann der Nucleolus folgenden Anblick bieten: an einer centralen großen Vacuole (?) sitzen drei, vier kleinere, etwa sichelförmig erscheinende Vorwölbungen, unter sich verschieden groß (Fig. 14, 18). Dieses Bild erinnert allenfalls an gewisse Zustände des noch im Wachsen begriffenen Ovarialnucleolus (Fig. 7).

Hieran schließe sich eine andre, ebenfalls seltenere Form, die einzige, an der färberisch Differenzierungen dargestellt werden konnten: an der Peripheric eines runden, sich mit Orange-G. gelb färbenden Körpers sitzen einige kleine durch HeidenHaIx geschwärzte Körnchen (Fig. 20, 22).

Schließlich tritt uns der Nucleolus als ein einfacher, dunkler, runder Körper entgegen, so wohl aber nur bei mangelhafter Differezierung. Bisweilen liegt der Nucleolus in einem hellen Plasmahof.

Es fragt sich nun, wie sind alle diese verschiedenen Bilder des Nucleolus zustande gekommen, beruht die Verschiedenheit nur auf ungleicher Differenzierung (oder Konservierung), wie Silvestri es von den seinen will, oder sind sie der Ausdruck verschiedener Zustände des Nucleolus? Ich möchte der letzten Ansicht zuneigen; denn ich erhielt auf ein und derselben Tafel die versehiedensten Nucleolustypen nebeneinander, die Färbung mit Orange-G. nach Heidesinas hatte auch durchaus nicht immer den obigen Erfolg, und wenn auch die Differenzierung auf einer Tafel (bei HeidexhaIx!) sehr ungleichmäßig aus- 
zufallen pflegt, so ist es doch kaum möglich, mindestens die Differenzierungeu in der Gestalt dadurch allein zu verstehen.

Wenn wir uns an die Nucleolusverhältnisse im Ovarialei erinnern, so fanden wir dort bei gleicher Konservierung und Färbung noch nicht eine so weitgehende Differenzierung wie hier und wir können der Angabe Silvestris nicht beipflichten, daß der Nucleolus sich unverändert erhalte.

Aus diesen Beobachtungen könnte vielleicht der Schluß gezogen werden, daß im abgelegten und selbständig gewordenen Ei mit dem Nucleolus Veränderungen vorgehen, die in seiner wechselnden Gestalt und Struktur ihren Ausdruck finden. Ob diese Veränderungen in irgendwelchem Zusammenhange mit den Reifungsvorgängen stehen, konnte nicht erkannt werden; es scheint, daß beide Erscheinungen unabhängig voneinander sind.

Im Polarteil des reifen Eies liegen die Richtungskörper $\left(p_{1}\right.$. $p_{2}$ ). In gar nicht so seltenen Fällen fanden wir statt der normalen drei neben zwei normal ausgebildeten einen in mehrere kleine Stiickchen »zerfallenen «oder auch vier, ja fünf gleich große. Wie diese MehrzahI entstanden ist, vermag ich nicht anzugeben. Die drei Richtungskörper sind unter sich gleich groß. Ihre Gestalt wechselt zwar, doch hebt sich eine bestimmte Form als typisch und sehr charakteristisch besonders hervor: die Richtungskörper sind dam gleichmäßig länglich bis kommaförmig und von höchst unregelmäßiger Begrenzung, mit zahlreichen kleinen Vorsprïngen und Ecken, manchmal wie gekämmt aussehend (die Richtungskörper der Drohne (Petrunkewitsch 1901) oder von Rhodites rosae (Schleip 1910) sehen ähnlich aus). Sie färben sich immer gleichmäßig dunkel, bei HeIdenhain tiefschwarz.

Ihre Lagerung zueinander gestaltet sich im typischen Falle so, daß ein Kern polwärts gelegen ist, während die beiden andern, mehr central gelegenen einander genähert sind (Fig. 17). Silvvestri bildet diese typische Lage ebenfalls ab und bemerkt dazu, sie komme so zustande, daß der hintere Tochterkern des ersten Richtungskörpers sich dem 2. Richtungskörper nähere: das sei das in der Mitte gelegene Kernpaar; der vordere Tochterkern des 1. Richtungskörpers sei der polar gelegene Kern (so auch Doncaster bei Tenthrediniden [1906]).

Es scheint jedoch richtiger, den einzelnen polwärts gelegenen Richtungskörper $\left(p_{2}\right)$ als den 2. zu betrachten und das centrale Paar $\left(p_{1}\right)$ als die Tochterkerne des 1.; denn diese Deutung schließt sich aufs allerbeste dem oben geschilderten 3. Modus der 2. Reifungsteilung an, wo der 2. Richtungskörper am Pol, in der Mitte die Teilungsfigur des 
Zur Entwicklungsgesch. des polyembryonalen Chalcidiers Ageniaspis usw. 443

ersten gelegen war (Fig. 16). Daneben finden sich freilich auch reife Eier, wo alle drei Richtungskörper einander gleich genähert sind, parallel (Fig. 18) oder in einem Dreieck liegend (Fig. 22).

\section{Die Befruchtung.}

Der Befruchtungsvorgang, wie er von Silvestri geschildert wird, weist keinerlei Besonderheiten auf: das Spermatozoon rundet sich nach Schrumpfung des Schwanzes ab, vergrößert sich und wird zum männlichen Vorkern, der mit dem weiblichenVorkern verschmilzt.

Ich beobachtete das Spermatozoon $(s p)$ häufig in Gestalt eines homogenen, etwa kommaförmigen Körpers im Embryonalteil des Eies (Fig. 13) oder aber in seinem späteren Zustand als mämnlichen Vorkern, der sich in seiner Struktur vom Kern des reifen Eies nicht unterscheiden ließ (Fig. 18). Ebensowenig läßt sich ein Unterschied der beiden Vorkerne zu den späteren Furchungskernen finden, und man erhält gelegentlich Präparate, wo man im Zweifel sein muß, ob die zwei im Embryonalteil des Eies liegenden Kerne die beiden Vorkerne oder die beiden ersten Furchungskerne repräsentieren (vgl. auch unter »1. Furchung (). In einem Fall, wo die beiden sonst gleichen Kerne sich durch ihre Größe beträchtlich unterschieden, dürfte es allerdings wohl berechtigt sein, den kleineren Kern als Spermakern anzusehen, der seine definitive Größe (nämlich = Eikern) noch nicht erreicht hat.

\section{Die erste Furchung.}

Der Furchungskern, der Kern des reifen Eies, mag er befruchtet sein oder nicht, schickt sich nummehr zu Teilungen an.

Vorgänge im Embryonalteil: Teilungen - Nucleolus. An den Vorgängen am Kern selbst ließ sich nichts Erwähnenswertes beobachten. Fig. 21 stellt eine offenbare Prophase dar, Fig. 22 zeigt das Auseinanderrücken der Tochterhälften $\left(o_{3}\right)$; man erkennt hier, daß die Teilungsebene senkrecht zur Längsachse des Eies liegt.

Dieser 1. Teilung des Furchungskernes braucht num nicht immer sogleich eine Teilung des Embryoplasmas, also eine Zellbildung zu folgen, ein Fall, den auch Sruvestri kurz erwähnt und als cin gelegentliches Vorkommen bezeichnet. Die Schwierigkeit, einderartig gefurchtes Ei von einem mit zur Vereinigung bereiten Vorkern zu unterscheiden, wurde oben erwähnt; sie besteht fïr den Fall, daß die Richtungskörper auf dem Zustand beharren, den sie im reifen Ei zeigten. Präparate, wo sich im hintern Teil des Eies sogar drei Kerne finden, die doch wohl nur als Furchungskerne gedeutet werden kömnen, während in vordern 
Teil die Richtungskörper unverändert liegen, beweisen, daß Verschiebungen dieser Art in der Entwicklung des Ageniaspis-Eies vorkommen können. Liegen nun aber die beiden Kerne nebeneinander und nicht vor einander und ist die vom reifen Ei her bekamnte Plasmadifferenz noch deutlich erkennbar, dann können wir mit einiger Wahrscheinlichkeit annehmen, daß wir ein Ei mit den beiden Vorkernen vor uns haben. Deshalb nämlich, weil die Plasmadifferenz bei diesem Furchungstypus nit beginnender Teilung zu schwinden scheint, insofern sie wenigstens färberisch nicht mehr zum Ausdruck kommt.

Norma lerweise aber ist mit der Furchung eine Zellbildung und -teilung verbunden und dieser auch von Silvestri ausfiihrlicher beschriebene Furchungsvorgang nimmt folgenden Verlauf: schon der noch ruhende, aber kurz vor seiner Auflösung stehende Furchungskern liegt in einer deutlichen Zelle. Es hat sich offenbar das Embryonalplasma, das früher den hintern Pol des Eies gleichmäßig eimnahm, um den Furchungskern herum zusammengezogen, so daß es rings von dem Polarplasma (wemn wir es jetzt noch so nennen wollen) umgeben ist. Aber abgesehen von der Lage, scheint sich auch die Beschaffenheit der Plasmen geäudert zu haben: das Embryonalplasma nimmt einen geringeren Raum ein, als auf früheren Zuständen. Die Konservierung führt, zumal da das Embryonalplasma oder die »Furchungszelle gern geschrumpft ist, eine absolut scharfe Tremung herbei; es sei nur auf die Fig. 19-21, bl verwiesen - und schließlich ist auch hier ihr Verhalten gegen Farbstoffe geändert: es besteht nicht mehr der starke Unterschied, ja, das vorher dunklere Embryonalplasma erscheint sogar in der Regel heller, als das Polarplasma, eine Beobachtung, der wir indessen nicht allzuviel Wert beilegen möchten.

Diese Trennung der Plasmen bleibt von num an erhalten und wir treffen wohl das Richtige, wenn wir das Polarplasma, worin die Furchungszelle eingebettet liegt, als das 》Trophamnios Marchals $(t r)$ in seinem ersten Anfang betrachten; denn nach diesem Autor differenziert sich das Trophamnios erst anf viel späteren Stadien von dem die Furchungskerne umgebenden Embryonalplasma. Wir wollen daher von jetzt ab für »Polarplasma «die nummehr sinngemäßere Bezeichnung Marchals gebrauchen.

Silvestris Figuren lassen zwar erkennen, daß ihm dieselben Verhältnisse vorgelegen haben; im Text jedoch geht er darauf nicht ein. Die scharfe, frïhzeitige Herausdifferenzierung dieser »Furchungszelle « einerseits und des Trophamnios anderseits erscheint aber als ein sehr charakteristisches Stadium der Entwicklung. 
Schließlich muß noch erwähnt werden, daß der Nucleolus im Furchungsplasma eingeschlossen liegt.

Die semmelförmige Plasmamasse, in der die beiden jetzt entstandenen, ersten Furchungskerne zunächst noch liegen, teilt sich in der Mitte durch, die beiden Zellen runden sich mehr und mehr ab und rïcken nebeneinander, während sie erst voreinander lagen. Sie repräsentieren die beiden ersten, vollständig voneinander getrennten Blastomeren (Fig. $23 b l_{1}$ und $b l_{2}$ ).

Das Trophamnios sehmiegt sich allseitig an sie an.

Die Kerne der Blastomeren sind im Verhältnis zum Plasma ziemlich groß und zeigen meist periphere Chromatinkörnchen und ein zartes Netzwerk (Fig. 23), in andern Fällen erschienen sie als ein gleichmäßiger Haufen von Körnchen (Fig. 26).

Der Nucleolus (nls) nun ist bei der Zellteilung in eine der beiden Blastomeren übergegangen; er liegt an irgend einer Stelle in dem spärlichen Plasma, dem Kern meist angeschmiegt. Vergleichen wir seine Erscheinungsweise hier mit der im reifen und sich furchenden Ei, so muß hervorgehoben werden, daß er nie mehr als der zarte, duftige Körper erscheint, ebensowenig beobachten wir in ihm Vacuolen oder überhaupt ähnliche Differenzierungen, wie vorhin; vor allem aber ist die vorher unverkennbar vorhandene Konstanz der Größe und der allgemeinen Form geschwunden. Von der maximalen Größe der Fig. 24 bis zu solchen, deren Größe etwa der des Sehwanzanhanges in Fig. 24 gleich ist, finden sich alle Übergänge; ihre Form ist stabförmig, grade oder gebogen, bis mehr oder weniger abgerundet. Ich gebe in Fig. 26 einige Detailbilder davon. Häufig lassen sich in den Nucleolen bei Heidenhaix-Färbung - meist sind sie homogen schwarz — dunkle und helle Partien unterscheiden oder sie erscheinen aus mehreren Stiicken zusammengesetzt.

Jedenfalls bietet im allgemeinen der Nucleolus im gefurchten Ei ein durchaus andres Bild als im reifen - ein Verhalten, das Silvestri nicht beobachtet zu haben scheint. Im Hinblick darauf, daß der Nucleolus bald nicht mehr nachweisbar sein wird, darf man wohl in seiner soeben geschilderten Beschaffenheit eine Andeutung des Zerfalls erblicken.

Vorgänge am Trophamnios: Verwandlung der Richtungs körper in den Paranucleus. Wenden wir uns jetzt den parallelen Vorgängen am Trophamnios zu, vor allem dem Schicksal der Richtungsliörper. Eine Reihe besonders günstiger Präparate gestatten uns gewisse Ubergangsstadien genauer zu verfolgen. 
Wenn sich Furchungszelle und Trophamnios geschieden haben, beginnen bereits die Veränderungen der Richtungskörper: in Fig. 19 sieht man zwei Richtungskörper unverändert, während der dritte sich angenscheinlich in einige bogenförmige Körnchenreihen aufgelöst hat.

Ein andres, auch von Silvestri beschriebenes Stadium zeigt statt der Richtungskörper vier, fünf mehr oder weniger vollständige Kreise von Körnchen und in deren Innern ein zartes Geriistwerk - also kernälnnliche Gebilde (Fig. 20 p.n, die besonders ins Auge fallenden Granula sind auf Silvestris Figuren nicht wiedergegeben).

Daran schließt sich offenbar der auf Fig. 21 dargestellte Zustand: die »Kerne "lösen sich wiederum auf und fließen zusammen; deutlich erkennt man noch Reste der Körnchenkreise - der Furchungskern zeigt bereits eine Mitose.

Im gefurchten Ei schließlich haben die Veränderungen einen vorläufigen Abschluß erreicht mit der Entstehung des großen Trophamnioskermes, des »Paranncleus « MarchaLs. Dieser nimmt als ein vielfach eingebuchteter, gelegentlich gelappter, heller Kern, in dem sich außer den peripheren Körnchen spärliche Granulationen und regelmäßig einige gröbere Chromatinklumpen, sclten nur ein deutliches Gerïstwerk, finden, den weitans größten Teil des gesamten Trophamnios ein (Fig. 25 p.n).

Von diesem einzigen großen Kern findet sich bei Silvestri nichts, während Marchal ihn auf seinen älteren Stadien dentlich abbildet und beschreibt. Nach Silvestri bleiben die vielen "Kerne«ohne zusammenzufließen erhalten, mur seien sie »molto allargati e alle volte già in parte od in tutto frazionati o divisi direttamente et irregolarmente per il protoplasma «. Im 12-Zellenstadium beginnen sich damn nach Sinvestri die »Kerne« in Körnchenhaufen anfzulösen und von da ab erst gebraucht er die Bezeichnung »Paranucleus «.

Ich wage nicht zu entscheiden, ob wirklich die Stadien in der obigen Reihenfolge miteinander zusammenhängen und ob wirklich auf diesem merkwïrdigen Wege die (als Tatsache an sich nicht zu bezweifelnde) Umwandlung der Richtungskörper in den Paranucleus vor sich geht. Die Seltenheit grade der Belege für die Fig. 19 und 21 mahnen zur Vorsicht.

Die auf diesen Stadien noch im wesentlichen vom Trophamnios bestimmte Gestalt des Eies ist schließlich mehr oder weniger abgerundet geworden, in seltenen Fällen ist sie noch langgestreckt; im vordern Teil - wem man dies kngelige Ei noch so orientieren will, wie früher 
Zur Entwicklungsgesch. des polyembryonalen Chalcidiers Ageniaspis usw. 447

- liegt der Paranucleus, im hintern, banchig erweiterten, peripher die Furchungszellen.

Das Chorion wird nicht mehr beobachtet.

\section{Die zweite Furchung und die folgenden.}

Veränderungen des Embryonal teils: Teilungen - Schicksal des Nucleolus. Nach Silvestri findet die 2. Furchung nicht gleichzeitig in den beiden ersten Furchungszellen statt, und zwar ist das Vorhandensein des Nucleolus entscheidend: die vom Nucleolus freie Blastomere teilt sich eher als die Nucleolus-haltige. Das Resultat ist also zunächst ein 3-Zellenstadium. Auf diesem Stadium ist jedoch nach Silvestri der Nucleolus gar nicht oder allenfalls nur durch die stärkere Färbbarkeit des ihn in aufgelöster Form enthaltenden Plasmas nachweisbar. Keine der von Silvestri hierzu gegebenen Figuren jedoch kamn als eine Illustration der geschilderten Teilungsvorgänge dienen. So zeigen die hier in Betracht kommenden Textfiguren VII und IX drei sich durch nichts voneinander unterscheidende Blastomeren! Und Mitosen selbst sind nicht abgebildet.

Ich vermag indessen die von Silvestri angegebene Teilungsversehiebung durchaus zu bestätigen. Ein Blick auf Fig. 24 zeigt ein 2-Zellenstadium. Der Kern der einen Blastomere $\left(b l_{1}\right)$ ist in mitotischer Teilung begriffen - leider war es nicht möglich, irgendwelche Einzelheiten an der Teilungsspindel genauer zu erkennen —, das Zellplasma sieht mit seinen unregelmäßigen Konturen gewissermaßen gelockert aus und hebt sich da, wo es das Trophamniosplasma berührt, nur wenig von diesem ab. Der Kern der andern Blastomere $\left(b l_{2}\right)$ hingegen ist vollkommen in Ruhe. Über diesem Kem aber gewahren wir als ein gerade in diesen Präparat besonders großes und bizarres Gebilde den Nucleolus $(n l s)$.

Es darf wohl hierin der Beweis dafür erblickt werden, daß die mit dem Nucleolus behaftete Furehungszelle sich später teilt als die nucleolusfreie.

Ein Schritt weiter, die Teilung hat sich vollzogen und wir erhalten das 3-Zellenstadium.

Was aber den Nucleolus auf diesem Stadium betrifft, so sagt Silvestri darüber: Der bisher in einer der beiden Embryonalzellen immer sehr deutliche Nucleolus beginnt. wenn die Teilung der nucleolusfreien Zelle herankommt »a frazionarsi e a disperdersi per il protoplasma della cellula che lo contiene, così che quando si hanno tre cellule 
embrionale esso non si rileva affatto o poco e solo per la maggiore tingibilità del protoplasma di detta cellula «.

Meine Beobachtungen indessen lassen mich diese wie gesagt durch Abbildungen nicht belegten Angaben Silvestris bezweifehr. Der Nucleolus ist nämlich nicht nur auf dem Stadium, auf das sich die soeben zitierten Daten Silvestris beziehen, also während der Teilung der freien Blastomere, noch klar nachweisbar, wie wir ja oben sahen (Fig. 24), sondern er ist auch auf dem 3-Zellenstadium durchgehends noch vorhanden. So sehen wir in Fig. 25 in einer der drei Blastomeren zwei kleine Einschliisse (nls), die wir als vom Nucleolus herrïhrend deuten möchten, und so war immer auf den zahlreichen 3-Zellenstadien, die mir zur Verfügung standen, die eine Zelle durch Einschlüsse ausgezeichnet.

Wenn wir aber die Nucleolen dieses Stadiums vergleichend betrachten (Fig. $27 \mathrm{nls}$ ), so fällt uns die bedeutende Größenabnahme einerseits und das Auftreten mehrerer Einschlïsse anderseits - zwei oder drei wurden häufig beobachtet — auf. Wie ich glaube, vollzieht sich hier der oben beim 2-Zellenstadium schon angedeutete und von Silvestri bereits auf das Ende jenes Stadiums verlegte Zerfall des Nucleolus.

Verfolgte Silvestri bisher die beiden Ageniaspis-Formen parallel in ihrer Entwicklung, so hören hier beim 3-Zellenstadium seine Beobachtungen an der Ageniaspis der Iyponomeuta auf. Da sich dabei keine Abweichungen zwischen den beiden Ageniaspis ergeben haben, so sei es immerhin gestattet, daß wir im Folgenden unsre Beobachtungen an der Hyponomeuta-Ageniaspis vom 4-Zellenstadiun ab mit den entsprechenden Silvestris an der Subspezies "praysincola« vergleichen.

Weiterhin setzen vom 4-Zellenstadium ab auch die Beobachtungen Marchats ein an der Ageniaspis aus Hyponomeuta mahalebella, die freilich nur beschränkt zum Vergleich herangezogen werden können, da Marchal den Nucleolus nicht kannte.

Silvestri führt die Entwicklung folgendermaßen weiter: die 3. Blastomere, in deren Plasma der Nucleolus sich aufgelöst hatte, teilt sich schließlich auch-4-Zellenstadium; bei der nächsten, 3. Furchung, teilen sich diese beiden Zellen nicht, wohl aber die beiden nucleolusfreien und wir erhalten 6 Zellen. Die 4. Furchung bringt die Zahl der nucleolusfreien Zellen von 4 auf 8 und die der nucleolushaltigen von 2 auf 4, gibt - 12 Zellen (die weiteren von Silvestri nicht so schrittweise verfolgten Veränderungen vollziehen sich in der frisch geschliipften Prays-Raupe). Freilich ist weder aus den Abbildungen der jeweiligen Endstadien, noch aus der Beschreibung zu ersehen, wie es möglich war, 
die zwei Blastomerenarten auseinanderzuhalten und getrennt zu verfolgen (besondere Färbbarkeit? Lagerung im Ei?).

Mir war es leider nicht möglich, die Entwicklung der HyponomeutaAgeniaspis so Schritt für Schritt weiter zu studieren. Es ergab sich jedoch, daß im 4-Zellenstadium alle Blastomeren einander gleichen und daß entgegen den Beobachtungen Suluvestris erst ron diesem Stadium ab der Nucleolus weder als geformter Bestandteil noch als Plasmadifferenz nachweisbar ist (so auf 5-, 6-, 7-Zellenstadien).

In der Lagerung und $\bar{F}$ orm der Blastomeren stimmen die Verhältnisse hier mit den von Silvestri beobachteten überein, während Marchals Ergebnisse auch hier für den Vergleich nicht in Betracht kommen können, denn nach ihm sind die Kerne der Blastomeren, ohne daß eine Zellbildung eingetreten wäre, "plongés dans la masse protoplasmique de l'œuf «, auch noch auf dem 12- und mehr-Zellenstadium. Nur soviel sei vom 3-Zellenstadium ab vorläufig allgemein gültiges hinzugefïgt:

Die Gestalt der Zellen bleibt bei der Zunahme ihrer Zahl nicht immer rund, wie auf dem 2-Zellenstadium; vielmehr platten sich die Blastomeren aneinander $a b$ und schmiegen sich in die Buchten des Trophamnions ein; ihre Kerne sind im Verhältnis zum Plasma ein wenig kleiner geworden (so auch auf Silvestris Abbildungen) und sie zeigen vielfach einen ron SilvestRi nicht beobachteten, exzentriseh gelegenen Nucleolus.

Veränderungen des Trophamnios: Paranucleus -- Plasmadifferenz. Das Trophamnios hingegen hat gewisse Veränderungen erlitten, die Silvestri, soweit er sie überhaupt beobachtete, schon im 2-Zellenstadium einsetzen läßt, die sich mir aber erst vom 3-Zellenstadium ab bemerkbar gemacht haben und auch da erst noch in den Anfängen.

Wir konstatieren nämlich eine fortsehreitende Vacuolisierung (in einem vereinzelten Fall enthielt auch eine Blastomere eine Vacuole). Selten handelte es sich dabei um eine große Vacuole (so MarchaL), sondern in der Regel sind es mehrere, ja viele, kleine, die gelegentlich miteinander verbunden sind und bisweilen an den Stellen des Trophamniosplasma, wo es als nur zarte Wand den Hohlraum begrenzt, in dem die Blastomeren liegen, eine unförmige Auftreibung bilden.

Vor allem aber beobachten wir eine Differenzierung des Plasmas selbst, die wir bei Marchal und Silvestri nieht beschrieben finden, so zwar, daß wir auf dem 6-Zellenstadium etwa unterseheiden können zwischen einer centralen Trophamniosmasse - diese ist zart schammig 
oder wabig, deutlich granuliert und daher dunkel - und einer sich scharf davon abhebenden peripheren Masse, die durchaus homogen als eine schmale Zone das ganze Ei nach außen abgrenzt (Fig. 28 eht und ent, Anfänge schon in Fig. 25), eine Differenzierung, die etwa an das Ekto- und Entoplasma einer Amoebe erinnert. Es muß aber hervorgehoben werden, daß diese Bildung individuellen Schwankungen unterworfen ist und in gewissen Beziehungen zu den Verhältnissen steht, die im nächsten Abschnitt besprochen werden sollen.

\section{Biologische Beobachtungen am Ei von der Ablage bis zum Schlïpfen der Hyponomenta.}

Wenn wir unsre Aufmerksamkeit den Beziehungen zuwenden, die zwischen dem Ageniaspisei und dem Ei des Wirtstieres bestehen, so ist die uns zunächst interessierende Frage die: ist der Zeitpunkt der Infektion durch das Ageniaspisweibchen in bezug auf den Entwicklungszustand des Hyponomeuta-Geleges fixiert, so daß etwa eine gewisse Parallelität der beiderseitigen Entwicklung besteht?

Aus Marchals Angaben können wir nur entnehmen, daß die 4-Zelleier in schon hoch differenzierten Embryonen anzutreffen sind; Silvestri fand die Stadien bis zu 12 Zellen in Prays-Eiern »a periodo di sviluppo molto vario."

Diesen unbestimmten Aussagen gegenüber kann ich die folgenden Beobachtnngen anführen: die höchstens fünf Stunden alten 158 reifenden und noch oval geformten Eier fanden sich nur in Gelegen, die nicht weiter als bis zur Versenkung des noch undifferenzierten Keimstreifs entwickelt waren.

Das Gros der insgesant 206 zwei- und dreizelligen, etwa 1-2 Tage alten Eier wurde in Gelegen, in denen der Keimstreif sich zu differenzieren begann, gefunden

und die aus später zı erörternden Gründen nur sehr spärlichen etwa $20-4-9$ zelligen Eier in bereits wohldifferenzierten Embryonen. die seit etwa 10 Tagen infiziert waren.

So grob diese Angaben sind, es ist doch soviel daraus zu erkennen, daß die Entwicklung von Wirts- und Schmarotzerei in einem gewissen Verhältnis nebeneinander herläuft. Das Ageniaspis- + muß also eine Auswahl unter den IIyponomeuta-Gelegen treffen, die es zum Zwecke der Eiablage besucht. Wenn man num beobachtet, wie das Mottengelege scin anfängliches Wachsgelb verlierend, bald ein schmutziges Grün-brann aufweist, eine Farbänderung, die vermutlich einer Erhärtung der Chitinhüllen parallel läuft und beides wieder der Ent- 
wicklung der Schmetterlingseier, so liegt es nahe, zu vermuten, daß die Härte der Eihäute entscheidend ist für die Belegung. Ob das Muttertier durch Betasten mit den Antennen oder vielleicht einfach am mechanischem Widerstand, den der Legebohrer beim Ansetzen erfährt, die geeignete Schalenhärte und somit das ungefähre Alter des Eies vermittelt bekommt, wurde nicht beobachtet.

Im Anschluß hieran sei erwähnt, daß die Angaben des absoluten Alters der Entwicklungsstadien bei SiLvestri genauer und detaillierter sind, als die oben von mir angefïhrten; doch stimmen beide im großen Ganzen überein.

Ort der Infektion. Schwieriger gestalten sich die Dinge bei der Erörterung: wohin, in welche Teile des Wirtseies werden die AgeniaspisEier abgelegt, verteilen sie sich wahllos oder werden gewisse Elemente oder Partien vorzugsweise belegt?

MarchaL beschäftigt sich ausführlicher mit diesem Punkte; er fand die Parasiteneier vom 4-Zellenstadium ab ausschließlich in der Leibeshöhle des Raupenembryos, wegen des geringeren Beobachtungsmaterials wagt er jedoch nicht zu schließen, daß die Eier tatsächlich stets direkt in den Keimstreifen bzw. das Blastoderm der Hyponomeuta gelegt worden sind oder vielleicht secundär dahinein gerieten, wobei er Erwägungen anstellt, wie es im ersten Falle der legenden Wespe möglich sein könnte, grade die Embryonalzellen der Hyponomeuta mit dem Stachel herauszufinden.

Nach meinen Beobachtungen kann dem anch von einer Bevorzugung gewisser Elemente oder Regionen des Hyponomeuta-Eies keine Rede sein; wie die folgenden Zusammenstellungen über die Lagerungsverhältnisse zeigen werden:

von den reifenden Eiern lagen $133 \mathrm{im}$ Dotter (und in der Serosa),

5 am Blastoderm bzw. Keimstreif, 8 im Blastoderm und 14 zwischen Blastoderm und Chorion.

Wohl liegt hier bei weitem die größte Menge der Eier im Dotter; wenn man aber bedenkt, daß der Dotter ja die Hauptmasse des Hyponomenta-Eies ausmacht, so ist diese Verteilung durchans nicht verwunderlich. Wir erkennen auch, daß nieht ein bestimmter Bezirk, rein topographisch - etwa dureh die Stachellänge bedingt, wie es MarchaL als möglich hinstellt - bevorzugt wird, denn wenn auch die Hauptmenge in der centralen Eimasse liegt, so werden doch anch die peripheren Teile des Eies belegt, wohin die Parasiteneier durch sekundäre Strömungen und Versehiebungen kaum gelangen können: so etwa zwischen Blastoderm und Chorion oder - ein höchst seltenes 
Vorkommnis - in den Plasmaleib einer Serosazelle. Daß diese peripheren Stellen, die ja als gar nicht mehr zum eigentlichen Ei gehörig von vorherein sehr wenig Aussicht für eine günstige Entwicklung der Parasiten bieten diirften, iiberhaupt belegt werden können, erklärt sich vielleicht aus der in jedem Gelege verschiedenen Stellung der $H y$ ponomeuta-Eier, die bald flacher, bald steiler aufgerichtet dem Evonymuszweig aufliegen.

Für die zwei- und dreizelligen Eier, die wir ïbrigens als die häufigst - beide ungefähr in gleicher Menge - gefundenen und somit wohl auch verhältnismäßig lange beibehaltenen Stadien zusammennehmen können und die vorzüglich in Eiern mit beginnender Differenzierung des Keimstreifs gefunden werden, gelten folgende Daten:

von 206 Eiern wurden 168 im Dotter und 36 am oder im Embryo gefunden.

Das sind ungefähr noch dieselben Verhältnisse, wie wir sie bei den reifenden Eiern vorfanden.

Bei den älteren Eiern hingegen von 4 bis 9 Blastomeren ändert sich das Bild: ein 4-und ein 6-Zellenstadinm lagen im Dotter, ein 4-Zellenstadium in der Serosa, die 15 andern sämtlich in der Leibeshöhle, wie anch Marchal angibt, den Nerven einerseits und anderseits dem Ektoderm des Raupenembryos angelagert.

Diese absolnt geringe Zahl älterer Eier und ihre Lagerung im Embryo der Motte ist kein Zufall, wie sich im Folgenden zeigen wird.

Es soll nummehr nntersucht werden, wie das Wirtsei gegen die Parasiteneier reagiert, mit denen es so wahllos, wie wir eben sahen, belegt worden ist.

Degeneration der Dottereier. Unter den 2- und 3-Blastomereneiern, soweit wir ihnen im Eidotter begegnen, treffen wir auf eine sehr große Anzahl, die ein absonderliches Aussehen haben, etwa wie es auf Textfig. 3 dargestellt ist. Anfangs glaubte ich eine mangelhafte Konserviernng hierfür verantwortlich machen zu müssen; denn beim Vergleich dieser Präparate mit Silnestris Abbildungen fiel das ganz beträchtlich » geschrumpfte «Trophamnios auf mit seinem flachen Paranncleus ( $p . n)$; wie ein Ring erscheint es, in dessen Lumen die Blastomeren mit dem hier grade oft sehr deutlichen Nucleolus (nls) gelegen sind. Daher mögen diese überans charakteristischen Eier als »Ringeier « bezeichnet werden.

Nanche der Ringeier stellen offenbar einen im Simne der soeben geschilderten Veränderungen fortgesehrittenen Zustand vor (Textfig. 4): der Hohlram des Trophamnios liat sich vergrößert, der »Ring « ist 
schmaler geworden, an einer Seite ist er leicht verdickt - hier liegt der Paranucleus, freilich nicht mehr als Kern, sondern als ein Haufen von Körnchen; die Blastomeren schließlich sind untereinander nicht mehr gleich groß, sie beginnen also offenbar ebenfalls an Größe zu verlieren. Es kommt auch vor, daß das Trophamnios brezelförmig zwei Hohlräume nebeneinander umschließt (Textfig. 5), von denen der eine

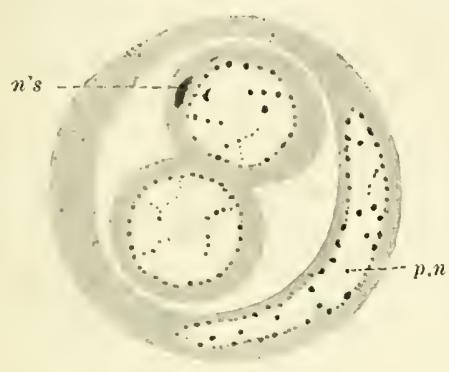

Textfig. 3.

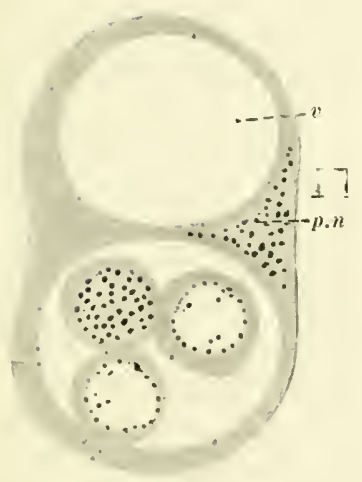

Textfig. 5.

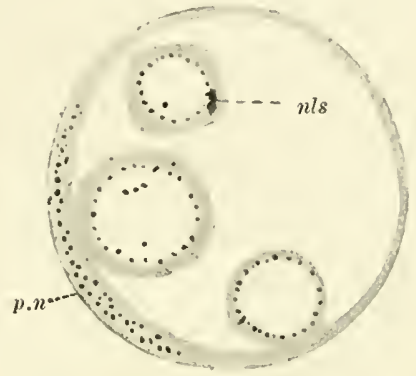

Textfig. 4.

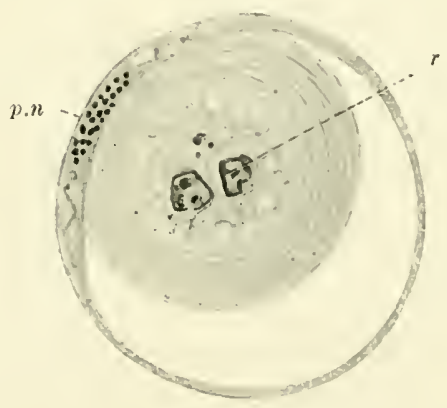

Textfig. 6.

Optische schnitte dureh sRingeier, die fortschreitende Degeneration der im \#yponomeuta-Eidotter liegenden Ageniaspis-lier zeigeud. p.n, Paranucleus; nls, Nucleolus; v, Vaenole; r, Reste der Blastomerenkerne.

die Furchungszellen enthält, während der andre $(v)$ vielleicht einer iiberaus großen Vacuole seine Entstehung verdankt.

Weiterhin beobachtete ich Gebilde, die ich hier anschließen zu dïrfen glaube, zumal da sie auch in $31 / 2$ und 10 Tage (seit der Infektion) alten Eiern, also älteren als die mit obigen Ringeiern, gefunden wurden (Textfig. 6). Ein bis auf die mit den Paranucleus-Resten be- 
setzte Stelle überaus schmaler Ring umschließt einen rundlichen, zart"glasigen « Körper; dieser ist konzentrisch geschichtet. Nach innen zu wird diese geschichtete Masse durch ein wabiges Plasma ersetzt und darin lassen sich einige (2 oder 3) kernähnliche Gebilde $(r)$ erkennen, die vielleicht als die Reste der Furchungskerne zu deuten sind. Diese Stadien finden wir nun aber nicht beliebig durch den Dotter verteilt, sondern sie werden nur noch an der Peripherie des Dotters beobachtet und vor allem in der Serosa, dort wo sie in dem anf den Schnitten als Ecken erscheinenden Äquator des linsenförmigen Hyponomeuta-Eies mächtig entwickelt ist (Fig 29).

Hier in dieser Randserosa sind fernerhin Körper gelegen, die eine gewisse Ähnliehkeit mit den bekannten Dotterkernen der Spinnen haben. In einer Vacuole des Serosa-Plasmas liegt ein konzentrisch geschichteter Körper mit einem zentralen, kernähnlichen Einschluß; es ist also, wenn wir mit dem vorigen Gebilde vergleichen dïrfen, der Ring vollständig geschwunden.

Und schließlich vermissen wir auch den centralen Einschluß, wir haben dann nur noch eine Vacuole und darin einen konzentrisch geschichteten Körper.

Wenn wir diese Beobachtungen zu deuten versuchen, so scheint es nahe liegend, in den geschilderten Veränderungen eine Degeneration der zwei- und dreizelligen Eier zu erblicken: das Trophamnios wird allmählich resorbiert, den konzentrisch geschichteten Körper darf man vielleicht als eine Umkapselung der Blastomeren deuten (?).

Soviel ist vor allem wichtig: wir finden die Ringeier nirgends anders als im Dotter, die Endstadien an der Peripherie des Eies und schließlich in der Serosa, wohin sie - man kann es sich vielleicht so vorstellen - durch Strömungen des Dotters gelangen müssen.

Von den $168 \mathrm{im}$ Dotter liegenden 2- und 3-Blastomereneiern waren 71 normal entwickelt, 97 dagegen zeigten Degeneration in mehr oder weniger hohem Grade; und wenn wir uns erinnern, daß die älteren Ageniaspis-Eier ausschließlich im Embryonalgewebe der Hyponomeuta gefunden wurden, so ist wohl die Annahme berechtigt, da $\beta$ alle die Eier, die in den Hyponomeuta-Dotter abgelegt wurden, bald zugrunde gehen. Das spricht auch Marchal vermutungsweise aus und Silvestri beobachtete bei Litomastix (1906) ähnliches: die Eier werden hier oft in Plusia-Eier gelegt, die schon wohlentwickelte Embryonen enthalten, und damn "puo accadere che l'uovo del Litomastix venga depositato nel tuorlo fuori dell'embrione oppure nell' intestino ed in ambedue tali casi esso va distrutto. "Näher geht Silvestri auf diese Erschei- 
nung nicht ein. In unserm Falle entwickeln sich die Eier nicht weiter als bis zu einem Stadium mit zwei oder drei Embryonalzellen.

Offenbar bediurfen also die Parasiteneier der Vermittlung der embryonalen Zellen ihres Wirtes zu ihrer Eruährung und vermı̈gen nicht den Dotter selbständig zu assimilieren.

Sehr häufig findet man eine Dotterzelle der Iyponomenta mit ihrem Kern angeschmiegt an das parasitische Ei — oder das Plasma dieser Zellen. das in feinen Strängen den Dotter durchzieht, umgibt das Ei allseitig und verschmilzt gradezu mit seinem Elitoplasma, so daß man an eine Beziehung trophischer Natur zwischen beiden denken möchte. Sie scheint indessen rein mechanisch zu sein, denn auch Ringeier waren sehr oft in dieser Weise mit Dotterzellen verbunden.

Hüllenbildung $u m$ die im Embryonalgewebe liegenden Eier. Wie verhalten sich nun Wirts- und Parasitenei zueinander in den Fällen, wo das Parasitenei ins Embryonalgewebe geriet, wo es Aussichten auf eine Weiterentwicklung hat?

Es war mir nicht möglich, zu verfolgen, auf welche Weise eigentlich das Ei von dem Gewebe des einfachen, undifferenzierten Keinstreifs gewissermaßen aufgenommen wird, so daß es schlicßlich in der Leibeshöhle des Embryos angetroffen wird. Wohl aber läßt sich dentlich beobachten, wie sehr bald das IIyponomeuta-Gewebe in innigere Beziehungen zu den Parasiten zu treten scheint.

Marchat komnte feststellen, wie sich an ein $8-10$ zelliges Fi mesenchymatöse Elemente des Wirtsgewebes anlegten, indem sie sich samt ihren Kernen abplatteten; es entstehe so die von BugNion als ein Amnios vom Ei selbst abgeleitete epitheliale Hïlle. Sinvestri läßt die Hïllenbildung erst auf späteren Stadien in der Raupe stattfinden, und zwar durch einen oder zwei Kerne, die von einer oder mehr Zellen des Fettkörpers herrühreı.

Die Hülle selbst wird uns später noch beschäftigen, hicr soll uns lediglich ihre Entstehung interessieren. Es war schon oben die Rede davon, daß Elemente des Dotter's immig mit dem Plasma der AgeniaspisEier verschmelzen kömnen. Prinzipiell der gleiche Vorgang scheint sich auch in Embryonalgewebe der Hyponomeutu wiederholen zu können. (Die ein späteres Stadium darstellende Fig. 28 gibt dennoch eine renügende Vorstellung davon.) Wir sehen, wie sich viele Teile des Fettkörpers (meist weniostens) hie und da mit dem Ei verbinden. so dab es gewissermaßen verankert erscheint; und zwar verschmilzt gelegentlich, wie es scheint, das Wirtsgewebe vollständig mit der äußersten Zone des Trophamnios-»Ektoplasma «. Da es mir bisweilen möglich 
war, zu beobachten. wie sich derart mit dem Wirtsplasma verschmolzenes Trophamnios-Ekitoplasma hier und da scharf von dem iibrigen Trophamnios abhob, so möchte ich glauben, daß die Hülle des AgeniaspisEies ihre Entstchung nicht immer allein der Anlagerung von Wirtsgewebe verdankt, sondern daß sich der Embryo selbst daran beteiligen kann.

Es sei noch erwähnt, daß3 bereits 5zellige Eier in Verbindung mit dem Wirtsgewebe zu treten begimnen.

\section{Das Ei in der Raupe (vor dem Eintritt der Polyembryonie; August-April).}

Ende August haben die Hyponomeuta-Embryonen ihre Entwicklung vollendet, doch sei, bevor wir ihr Schicksal und das ihrer Parasiten weiter verfolgen, an dieser Stelle eine kurze Bemerkung iiber die Eihäuteder $H$ y p o n o me u $t$ a eingeschaltet:

Jedes Ei besitzt zwei Hüllen: 1. ein dickes, deutlich lamelliertes (auf Schnitten!) Chorion (sekundäre Eihïlle) und 2. eine weitere Chitinschale als tertiäre Hïlle, von der es bei Bugnios heißt: »chaque œuf est... recouvert d'une sorte d'écaille ornée de petites cannelures «, und Marchal spricht von einer Art »de carapace écailleuse «, von der das Ganze bedeckt sei. Die Abbildung Marchals, die einen Schnitt durch ein Gelege, allerdings von Hyponomeuta mahalebella, darstellt, läßt zwar die Lamellierung des Chorions erkennen, aber es scheint fast, als unterscheide Marchal überhaupt nicht zwischen den beiden Eihäuten, es ist alles in eine Masse verschmolzen, so daß die Chorien der einzelnen Eier kontinuierlich ineinander übergehen.

Ich konnte auf Schnitten durch die Gelege von cognatella nicht nur beide Häute deutlich unterscheiden, sondern auch feststellen, daß jedes Ei von der 2. Schale tatsächlich umgeben ist, nicht nur bedeckt. Freilich ist diese $(I I)$, wie die beigegebene Skizze zeigen mag (Fig. 29), auf der Oberseite der Eier beträchtlich kräftiger entwickelt, als auf der Unterseite, wo sie so dünn ist, daß sie nur auf günstigen Präparaten verfolgt werden kann. An den Berührungsstellen verlileben die tertiären Hüllen miteinander.

Die Verschiedenheit der beiden Schalen kommt auch färberisch zum Ausdruck bei Anwendung von Heidenhaix und Orange G: dann ist nämlich das Chorion gelb - die tertiäre Hülle schön blau gefärbt.

Die kleinen Räupchen nun verzehren die Eihäute bis auf die oberen dicken Teile der tertiären Hülle, soweit sie frei nach außen liegt, und 
verbringen unter dem Schutz der so entstandenen, gemeinsamen Chitinkappe die ungünstige Jahreszeit.

Daß in dieser Periode entsprechend dem Entwicklungsstillstand des Wirtes auch die Entwicklung der Ageniaspis-Eier sich verlangsamt, ist einleuchtend. Immerhin gewahren wir einige charaliteristische Fortschritte, die wir - in einigem ron Marchal abweichend - im Folgenden beschreiben wollen. (Ob diese "période hivernale "Marchals der Hyponomeuta-Ageniaspis in der Entwicklung der Wintergeneration der praysincola-Form entsprechend zum Ausdruck kommt, darïber finde ich bei Siluestri keine Angaben.)

Die Lagerung der Eier. Die Leibeshöhle ist, wie in den Embryonen, so auch in den Raupen der Aufenthaltsort der Ageniaspis-Eier und hier scheint keine Partie ausgeschlossen zu sein: bald finden wir sie dem Darm anliegend, bald mehr der Haut genähert, dorsal in den Fettliörper eingebettet oder ventral zwischen die Ganglien, bald mehr kopfwärts, bald im Hinterende. In der Prays-Raupe ist nach Silvestri die Gegend hinter dem Kopf, am Ösophagus bervorzugt. Und MarchaL beobachtete, daß in den Raupen eines und desselben Geleges die Eier durchgehends eine ungefähr gleiche Lage zu den Organen eimnehmen, so daß man bei Untersuchung nur eines Geleges zu der Ammahme verführt werden könne, die Eier bevorzugten die Nachbarschaft eines bestimmten Raupenorganes. Zur Erklärung dieses Befundes nimmt Marchal an, daß die definitive Lagerung bereits bei der Ablage des Eies bestimmt worden sei, entsprechend dem gleichen Entwicklungszustand aller Eier eines IIyponomeuta-Geleges.

Vielleicht ist so auf eine ganz spezifische Determination bei der Ablage auch das merkwürdige Vorkommen von Eiern in den Schlundganglien zurückzuführen, wie ich es oft beobachten konnte. In Wirllichkeit liegen die Eier freilich nicht eigentlich innerhalb des Nervengewebes, sie sind nur samt ihrer Hülle derart eingeschmiegt, daß, so lange die Eier klein sind, die Konturen des Ganglions durchaus gewahrt bleiben, in einer Flucht verlaufen, selbst dann, wenn zwei Eier zugleich im Hirn liegen, was mitunter vorkommt.

Ob sich für diesen Fall eine spezifische Reaktion zwisehen Wirt und Parasiten ergibt, konnte ich nicht beobachten. Da ich in Friihjahrsraupen die Eier, die dann selbst so groß geworden sind, wie die Sichlundganglien, niemals mehr in so innigen Bezichungen zum Hirn fand, so könnte man vielleicht annehmen, daßsie ans dem Nervengewebe einfach durch ihr Wachstum herausdrängen (Textfig. 7 ).

Die Morphologie der Eier. Die Gestalt der Eier ist während 
dieser Periode kugelförmig, soweit es die Lage zwischen den Organen des Wirtes gestattet, mur im Frïhjahr (April) sehen wir mehr unregelmäßig begrenzte, elliptische Eier; ihre Größe nimmt in den Herbstmonaten noch deutlich zu: August 2.5 $\mu$, September $30 \mu$, Oktober $42 \mu$, bleibt während des Winters konstant, bis dann in Frïhjahr ein erneutes Wachstum einsetzt, so daß die Aprileier etwa 50 " dick sind (die Hülle mitgemessen).

Die Hülle, die wir bereits im Embryo in ihrer Entstehung beobachteten, umschließt nummehr das Ei vollständig. Doch sind die histologischen Beziehungen zum Wirtsgewebe im Herbst noch sehr imnige, so namentlich bei den im Fettkörper liegenden Eiern; selbständiger erscheint die Hülle der in die Schlnndganglien eingeschmiegten Eier.

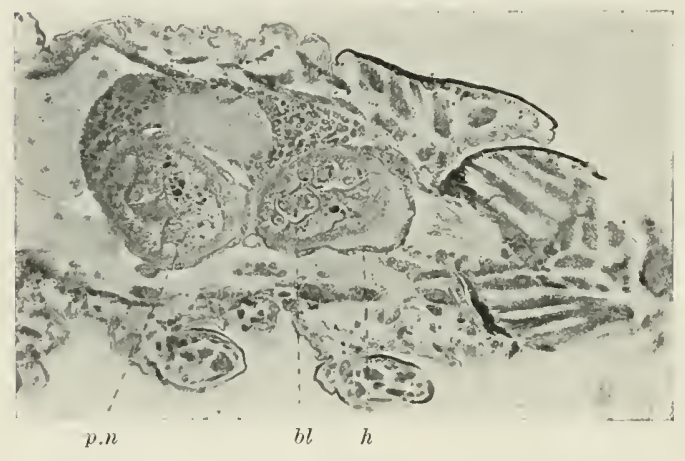

Textfig. 7 .

Zwei Ageniaspis-Lier im obereu schlundganglion einer Raupe, im Oktober. $h$, Hülle; $p . n$, Paranucleus; $b l$, Blastomeren. ZEISS F. 2. Daß z. B. auch in diesem Falle die Hüilenbildung vom Fettkörper ihren Ausgang genommen hat, wie es nach Silvestri allgemein gilt, wenigstens für die PraysForm der Ageniaspis, erscheint mir zweifelhaft; denn ich konnte anderseits beobachten, wie z. B. die peritoneale Unkleidung des Mitteldarmes direkt in das Eihiillgewebe überging.

Nach alledem ist es selbstverständlich, daß die Anordnung und Zahl der Hüllzellen im Herbst und Winter noch durchans ungeordnet ist; in Früjahr vervollkommnet sich der epitheliale Charakter der Hülle: die Zellen platten sich auf allen Seiten gleichmäßig ab und werden unabhängig von ihrem Muttergewebe, wofür die häufig beobachteten, tangentiale Teilungen einleitenden Mitosen der beste Ausdruck sind (Fig. 28 h zeigt die Hiille eines Oktobereies).

Bei der Subspezies praysincola zeigt die Hülle nach Silvestri ein ganz andres Aussehen: hier sind die Eier von einer cuticulaartigen "membrana protoplasmatica «, in der hier und da ein abgeflachter Kern liegt, umgeben. Wie diese Membran zustande kommt, wird von Silvestri nicht näher beschrieben; die Abbildungen zeigen sie von ihrem ersten Auftreten an in ihrer definitiven Ausbildung. 
Zur Entwicklungsgesch. des polyembryonalen Chalcidiers Ageniaspis usw. 459

Am Ei selbst unterscheiden wir, wie bisher, das Trophamnios und darin die eigentlichen Embryonalzellen.

Am Trophamnios begegnen wir wieder zu äußerst der zarten, ehtoplasmatischen Zone (eks) und weiter imen der eigentlichen Plasmamasse (ent), dunkler gefärbt und mit zahlreichen Vacuolen.

Diese Differenzierung bildet Marchal für diese Stadien zwar ab, ohne sie in Text zu erwähnen, aus der Farbengebung seiner Figuren die Ageniaspis-Elemente sind rot, alles Sekundäre, von der Raupe herrührende ist grau gehalten - geht jedoch hervor, daß MarchaL die periphere Zone für einen rom Wirtstier herrührenden Teil hält, wie es die Hülle ist; es ist aber nach dem im vorigen Kapitel Gesagten ihre primäre Zugehörigkeit zum Ei wahrscheinlicher.

Die Hauptmasse des Trophamnios ist erfüllt vom Paranucleus (p.n). Marchals eingehender Beschreibung ist kaum etwas hinzuzufügen: ein Kerngerüst vermochte ich nicht zu erkennen, wohl aber die Granulationen und die einzelnen größeren Klumpen. Die Granula sind nicht immer gleichmäßig verteilt (so bei Silvestri). In Oktober geht eine von MarchaL nicht beschriebene, sehr charaliteristische Veränderung im Paranuclus vor sich: Plasmastränge beginnen die Kernmasse einzukerbeı oder zu durchsetzen und so den Zerfall der einheitlichen Masse vorzubereiten (Fig. 28; es können übrigens nach MarcHaL auch zwei große einheitliche Paranuclei sich finden).

In der Lacune des Trophamnios gewahren wir den Embryonalteil des Eies. Nie sah ich die Paranucleusmassen ummittelbar an die Wand dieses Hohlraumes herantreten, wie es Silvestris Figuren zeigen, vielmehr bildet stets das Plasma des Trophamnios die Begrenzung. Nach Marchals Beobachtungen vollends finden wir vor Eintritt des Fruihjahrs auch jetzt noch keine Differenzierung der Plasmen: der Paranucleus und die Furchungskerne liegen in einer gemeinsamen Plasmamasse; bis dann die Kerne »disposés par groupes de 3 ou 4 « bestimmte Plasmabezirke um sich abgrenzen und sich so der Gegensatz zwischen »formativem « und »nutritivem " Plasma (Trophamnios) cinstellt.

Ich beobachtete die Gruppen ron 3 oder 4 \%ellen bereits im Oktober (Fig. 28, Textfig. 7), oft in besondern Bucliten des gemeinsamen Hohlraumes liegend; vorher, im August, traf ich noch regellosere Zellhaufen an und nur sehr spärliche Mitosen. Ich kann leider nicht genau angeben, ob die genamnten Zellgruppen durch Teilungen aus einer Mutterzelle hervorgehen; MARCHaL sagt. daß er dic Gruppen beobachtet habe, ohme daß sich die Kerne »d'une façon sensible "vermehrten. Im Frühjahr dagegen werden die Mitosen sehr zahlreich, die Zahl der Zellen hat 
beträchtlich zugenommen und sie drängen sich so dicht aneinander, daß sich nur hie und da noch eine der Zellgruppen isoliert zeigt.

Die Kerne der Furchungszellen besitzen, wie anch Marchal beobachtete, ein zartes Gerïstwerk und wenige Chromatinkörnchen; sie sind vor allem ausgezeichnet durch große Nucleolen, wenn man die sich intensiv färbenden, an Gestalt und Lage unregelmäßigen Bildıngen so nemnen kann.

\section{Der Polyembryo.}

Die Veränderungen nun, die sich vom Frühjahr ab in den Eiern abspielen und alle folgenden Entwicklungsvorgänge der Ageniaspis sind von Marchal und auch von Bugnion so eingehend behandelt und zum Teil vorzüglich illustriert worden, daß eine Nachprüfung, soweit sie unternommen wurde, die Angaben der genannten Forscher nur bestätigte. Es sollen daher hier lediglich der Abrundung der vorangegangenen Darstellung wegen die wichtigsten Daten aus der weiteren Entwicklungsgeschichte angeführt und nur einige Bemerkungen eingeschaltet werden.

Das, wie wir sahen, schon länglich gewordene Ei wächst, zum »Polyembryo « geworden, immer mehr in die Länge, bis es in der etwa 0,8 bis $1 \mathrm{~cm}$ langen Raupe (Mai, Juni) zu einem vielfach den Wirt an Länge übertreffenden, ganz unregelmäßig zusammengeknäuelten und verzweigten, wurstähnlichen Gebilde geworden ist.

Im Imnern des Eies vollzieht sich der Zerfall des Blastomerenhaufens in einzelne Massen, die isoliert im Trophamnios liegen. Von praysincola beschreibt Silvestri das gleiche Verhalten. Die Einzelmassen der Hyponomeuta-Ageniaspis jedoch teilen sich alsbald wiederum "par fractionnement « und diese sekundären »Morulae « repräsentieren die eigentlichen Embryonen. Der Polyembryo ist jetzt etwa $1 / 2 \mathrm{~mm}$ lang. Dieser sekundäre Zerfall unterbleibt bei dem nur 10-15 Embryonen liefernden Polyembryo der Praysincola.

Es wäre wohl lohnend gewesen, diese Beobachtung Marchals zu wiederholen, leider aber versagte durch einen merkwürdigen Zufall mein Material: keine der entsprechenden von mir untersuchten Raupen war infiziert.

Die Embryonen sind anfänglich rund, wachsen und werden erst länglich, dann nierenförmig, so zwar, daß die konvexe Seite ventral gelegen ist.

Ich füge hier ein, daß ich diese nierenförmigen Embryonen daraufhin untersucht habe, ob sich etwa einzelne Zellen als Geschlechts - 
zellen und als Nachkommen der mit Nucleolarsubstanz versehenen Blastomeren erkennen lassen. Das Ergebnis war ein negatives. Die iiberhaupt einzige Differenzierung ist, daß die im Centrum des Embryos gelegenen blasigen Zellen ein mehr gelockertes Gefüge haben und sich vermutlich als Entodermzellen um einen Hohlraum arrangieren (etwa Textfig. $8 \mathrm{em}$ ).

Erst in älteren, bereits segmentierten und gestreckten Embryonen, in denen sich Darm, Nerven und die mächtigen aus auffälligen, großen Zellen zusammengesetzten Speicheldrüsen unterscheiden lassen, habe ich die Gonaden beobachten können. (Über die Entstehung dieser Organe, außer den Gonaden, findet man bei Marchal Näheres.) Man erkennt sie als solche aber eben nur an ihrer typischen Lagerung und elliptischen Gestalt, ohne daß sich die Zellen durch besondre Färbbarkeit oder Einschlïsse von dem benachbarten Gewebe unterscheiden.

Während die jüngsten beobachteten Gonaden noch innig zwischen die Organe des Raupenembryos eingebettet sind, hängen die der fast fertig entwickelten Embryonen an der dorsalen Wand der Leibeshöhle, von einer Hülle umgeben und bieten nichts besondres.

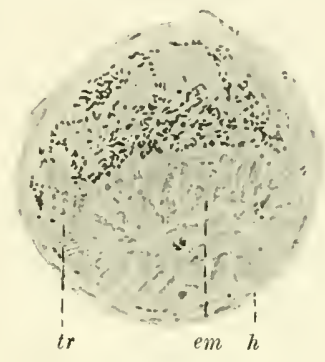

Texifig. 8 .

Querschnitt durch einen Keim. schlauche. Das Trophamuios $(t r)$ ist erfüllt von Bakterien. $h$, Hülle; $\mathrm{em}$, Embryo. ZEISS E. 2.

Mitte Juni haben die Larven ihre eigentümlich gedrängte und abgekürzte Entwicklung beendet und verlassen den Keimschlauch, indem sie sich gleichzeitig ein erstesmal häuten.

Das Trophamnios nimmt zunächst entsprechend dem Wachstum des Polyembryos an Masse zu. Der Paranucleus zerfällt, was wir schon im Winterei angedeutet sahen, in zahlreiche, zunächst größere Stïcke (daneben aber fand ich im Trophamnios oft noch dichte Wolken von Granulis in der Nähe der Embryonen). Am Plasma des Trophamnios unterscheiden wir im Gegensatz zu MarchaL zwischen dem schanmigen, dunkler färbbaren Entoplasma und der zarten Außenzone.

Die älteren Embryonen, schon die nierenförmigen, drängen das Trophamnios wesentlich zurück, bis nur noch dümne Scheidewände zwischen den einzelnen Individuen und gegen die epitheliale Außenliülle übrigbleiben. Die Teilstiicke des Paranucleus sind weiter in eine große Menge kleinerer und sehr kernähnlicher Teile zerfallen, die sich 
über das gesamte Trophamnios verteilen; das gesamte Plasma aber ist zu einer reich mit Stoffwechselprodukten beladenen Masse geworden: die nach Osmiumkonservierung geschwärzten Fettkörner, die in den mannigfachsten Größen und Formen vorkommen, scheinen nach meinen Beobachtungen in ihrer Menge individuell außerordentlich zu wechsehn: manche Keimschläuche waren fast schwarz, bei andern lagen nur einige wenige Körnchen zwischen den Embryonen (verschiedener Ernährungszustand der Wirtsraupe?).

Am Ende zerfallen die Parannclenskerne und das gesamte Trophamnios verwandelt sich in eine Substanz »d'apparence albumineuse « (Marchal), die den jungen Larven direkt zur Nahrung dient.

Die Hülle verhält sich während all dieser Vorgänge unverändert, nachdem sie zu einem typischen Epithel geworden ist. Dieses hat nach außen eine zarte Cuticula abgeschieden, auf der sich die Tracheen des Wirtes verzweigen.

Anhangsweise sei hier erwähnt, daß ich gelegentlich in den Keimschläuchen bakterienähnliche Gebilde angetroffen habe. Sie erfüllten in dichter Menge vorzüglich das Trophamnios, im Embryo fand ich mur vereinzelte, selten einige in der Huille. Die Photographie, Textfig. 8 mag eine ungefähre Vorstellung von ihrer Verteilung geben.

Sie sind kleine, gedrungene Stäbchen, an beiden Enden stumpf; oft färben sich die Enden nicht mit.

Da ich diese Gebilde auch in einem zufällig mitgeschnittenen Stück Raupenfettkörper antraf, wenn auch nicht in so enormen Ilengen, wie im Trophamnios, möchte ich glauben, daß der Keimschlauch vom Wirtsgewebe aus infiziert wurde. Denn grade aus Lepidopteren kennen wir, wie ich der Znsammenstellung von Buchner (1912) iiber »intracelluläre Symbionten « entnehme, ähnliche, gelegentlich auftretende Gebilde. Die von Zick (1911) in den Hoden von Pieris brassicae gefundenen bakterienähnlichen Körper scheinen den von mir gefundenen am nächsten zu kommen.

\section{Die postembryonale Entwicklung.}

Was dic postembryonale Entwicklung und den Ban der Larve von Ageniaspis betrifft, so gilt das am Eingang des vorigen Abschnitts Gesagte; ich muß, wie auch Marchal, auf die Darstellung Bugnions verweisen.

Die nach Bugnion 1.2 mm langen Larven verzehren in wenigen Tagen die Organe ihres Wirtes bis auf die chitinigen Tracheen, so daß 
schließlich die Raupe, wenn sie im Begriff ist, sich einzuspinnen, eigentlich nur einen von Parasiten erfüllten Chitinsack darstellt.

Jetzt häuten sich die Ageniaspis zum zweitenmal und verpuppen sich, indem sie sich ein drittesmal häuten. Dabei bleiben sie innerhalb dieser zweiten, erhärtenden Haut liegen, wie die Tönnchenpuppen der Dipteren. Dies heben Marchal und Silvestri mit Recht im Gegensatz zu Bugniox hervor, der die Puppenwiege als Produkt der Speicheldrüsen betrachtet; aber die, wie ich beobachtete, sehr deutlich erkennbaren Stigmen lassen keinen Zweifel über die Natur der Puparien.

Die so charakteristischen von den Puparien erfiillten Raupensäcke wurden bereits geschildert.

\section{Blologisches.}

Über die Naturgeschichte der Ageniaspis fuscicollis seien noch einige Bemerkungen hinzugefügt.

Nach einer dreiwöchigen Puppenruhe (Bugniox) schlïpfen die Ageniaspis aus. (Bei der Ageniaspis der Olivenmotte besteht ein ähn-liches Verhältnis zwischen dem Termin des Schlüpfens des Wirtes und dem des Parasiten, wie hier; nach Silvestri beträgt dort die Differenz 5-7 Tage.) Nach Bugnion verläßt die Ageniaspis der cognatella etwa in der Zeit vom 27. Juli bis 3. August ihre Puppenhülle, nur ausnahmsweise früher; in meinen Zuchten 1909 und 1910 dauerte die Schwärmzeit etwa einen Monat, von Mitte Juli bis Mitte August, so daß das Maximum allerdings am Ende Juli lag.

Der Akt des Auskriechens selbst bietet nichts besondres: das kleine Insekt 》taille à l'aide de ses mandibules une ouverture arrondie dans la peau de la chenille, développe ses ailes et s'échappe de sa prison « (Bugnion); das dauert wenige Minuten nur. Ehe -jedoch alle die 80 (oder wieviele es nun grade sein mögen) Geschwister die Haut ihres gemeinsamen Wirtes verlassen haben, vergehen schon mehrere Stunden; so schlïpften einmal in zweieinhalb Stunden 70 Individuen. Einige wenige Nachzügler kommen oft erst am nächsten Tag zum Vorschein. $\mathrm{Da}$ das Auskriechen sich in den hellsten Stunden des Tages vollzieht, erscheint bei diesem so außerordentlich lichtliebenden Tierchen selbstverständlich.

Das Benehmen der Inagines, die mit drolligem Eifer durcheinanderhasten und "une agitation fébrile « entwickeln. ist von den französischen Autoren unïbertrefflich elegant geschildert worden. Es sei nur noch besonders auf die lebhafte Tätigkeit der Antennen hingewiesen. die. 
indem sie fortwährend die Unterlage betrillern, als ein viertes Paar Beine mitzuremnen scheinen.

Höchst auffällig — darin kann ich Marchal nur beistimmen ist der starke Heliotropismus der Tiere: sie reagieren auf Lichtdifferenzen, selbst bei diffusem Licht, schneller und stärker als z. B. verschiedene Pteromalus-Arten, was man sehr gut beobachten kann, wenn man beide zugleich in einer Tube hält und das nach dem Fenster gelegene Ende nach dem Zimmer zukehrt. Man braucht z. B. die offenen Glastuben nur mit dem geschlossenen Ende nach dem Fenster zu zu legen, um sicher zu sein, daß kein Tier entkommt, ja man kann den Heliotropismus dazu benutzen, um die Wespchen bequem aus einem Gefäß in ein andres »überzuführen «.

Sind in unsrer Beobachtungstube beide Geschlechter vertreten, so bemerken wir gelegentlich in dem verwirrenden 》va-et-vient continuel le long des parois de verre "(Bugnion) eine Stockung: es findet eine Copulation statt; nach wenigen Sekunden trennen sich $\sigma^{\top 7}$ und 오 (so auch schon vou Bugrion beobachtet), um in dem Gewühl zu verschwinden. Und zwar begatten sich die Ageniaspis schon ganz kurze Zeit nach dem Ausschlïpfen, nicht erst, wie MarchaL angibt, 2 oder 3 Tage danach.

Bei der Eiablage lassen sich die Tiere durch den Beobachter oder durch Gerïche, wie den Terpentingeruch der Olfarbenmarkierungen, die ich anwandte, wenig stören. Der Vorgang selbst ist von MarchaL für die Hyponomeuta-Form und von Silvestri für die praysincola so ausführlich und anschaulich geschildert worden, daß nichts hinzuzufügen bleibt. Es sei auf die Abbildungen Marchals Taf. IX, Fig. 1 und 2 verwiesen; auf Fig. 2 sind freilich Kopf und Antennen des legenden ㅇ ganz beträchtlich zu klein gezeichnet! Häufig beobachtete ich mehrere 오우 zugleich auf einem Gelege, bis zu 7; auch wurde dasselbe Gelege sicher 3 Tage hintereinander von den 우우 eingehend betastet und untersucht und auch ganz ausnahmsweise noch einmal belegt; dann fand sich eben auf den Schnitten neben den bereits weiter gefurchten Eiern ein noch reifendes. Aber das kommt so selten vor, daß das oben bei der Biologie des abgelegten Eies Gesagte nicht im Geringsten betroffen wird.

Die sofortige energische Entfaltung der Lebenstätigkeit, wie sie im Vorhergehenden geschildert wurde, wird verständlich, wenn man bedenkt, daß unserm Chalcidier nur eine kurze Lebenszeit zur Verfïgung steht: in Bugnioss Tuben lebten sie 2-3 Tage, Marchal dagegen schließt aus der Menge des Auftretens in seinen Freizuchten, 
daß sie kaum länger als 10 Tage leben dürften. Bugrios suchte die Ursache für das baldige Sterben in Nahrungsmangel, doch vermute ich nach Beobachtungen an Tieren, die in der Gefangenschaft sorgfältiger behandelt wurden (man bedenke die Anspruchslosigkeit vieler Insekten in dieser Hinsicht!), daß auch im Freien die Ageniaspis nach so kurzer Zeit sterben.

Über die Anzahl der aus einer Hyponomeuta schlüpfenden Schmarotzer bringen meine Beobachtungen nichts neues: im Mittel sind es ungefähr 100 Stiiek, wie bei Marchal und Bugnion auch. Die Larven, bzw. Puppen der Prays oleellus beherbergen nach Silvestri nur 10-15 Individuen, entsprechend der geringeren Größe des Wirtes, der 6,5bis $7 \mathrm{~mm}$ lang und $1,3 \mathrm{~mm}$ breit ist.

Bemerkenswert scheint mir, daß die Ageniaspis fuscicollis außerordentlich konstant in ihrer Größe sind im Gegensatz zu andern in großen Mengen ein Wirtstier bewohnenden verwandten Hymenopteren: bei einem unbestimmten Pteromalus aus Pieris rapae z. B. zeigten namentlich die aus einer Puppe geschlüpften $Q$ 우 bedeutende Größenunterschiede; oder: bei Prestwichia aquatica Lubbock sind nach Heymoss (1908) unter den 11-16 Individuen, die aus einem Ranatra-Ei schlïpfen, einige kaum halb so groß als die anderm.

Das Verhältnis der Geschlechter gestaltet sich nach Bugrron so, daß in der Mehrzahl der Fälle die Geschwister von gleichem Geschlecht sind. Dieser Umstand war für Bugnion ein schwieriges Problem, da er ja die polyembryonale Vermehrung nicht kannte und alle die vielen Individuen aus ebensovielen von einem 우 unmittelbar hintereinander abgelegten Eiern hervorgehen lassen mußte. (Diese Gleichgreschlechtlichkeit ist schon lange von Pteromalus puparum bekannt.) In den andern Fällen aber schliipfen beide Geschlechter, und zwar entweder ungefähr zu gleichen Teilen oder aber ein Gesehlecht ist so bedeutend in der Überzahl, daß vom andern nur ein bis drei Individuen gezählt werden.

Auf Bugrioxs Erklärungsversuche wollen wir nicht näher eingehen. Beim gegenwärtigen Stand unsrer Kenntnisse ist es ja nicht verwunderlich, daß die aus einem Ei dureh Polyembryonie hervorgegangenen Geschwister gleichen Geschlechts sind. Erhalten wir verschiedene Geschlechter, so ist das Hyponomeuta-Ei, wie Marchal erklärt, mit mindestens zwei verschieden geschlechtigen Eiern, einem befruchteten und einem unbefruchteten belegt worden. Dasselbe vermutet Sirvestri für praysincolu.

Die Fälle nun mit dem extremen Úberwiegen des einen Geschlechts 
erklärt Marchal durch die Annahme, daß die Individuen des einen, in der Entwicklung ein wenig mehr fortgeschrittenen Keimschlauchs denen des jüngeren die Nahrung mit dem Erfolg streitig machen, daf diese Individuen zugrunde gehen bis auf einige wenige; wie es denn auch nach Marchal vorkommen soll, daß oft tote Larven, die sich aus Nahrungsmangel nicht weiter entwickeln kounten, in den Raupen gefunden werden. Dies ist mir übrigens bei meinen Untersuchungen nicht begegnet. So einleuchtend die Erklärung Marchals scheint, so sei doch auf die Merkwürdigkeit hingewiesen, daß Übergänge zwischen den extremen Fällen -1 bis 2 von dem in geringerer Zahl vorhandenen Geschlecht - zu den Mittelfällen — beide Geschlechter ungefähr gleich stark vertreten - unter den von Bugsion gegebenen Daten nicht zu finden sind. (Genügend umfangreiche eigene Beobachtungen stehen mir leider nicht zur Verfügung.)

Hier schließt sich die Frage nach der geschlechtsbestimmenden Bedeutung der Befruchtung an. Buginion meinte bereits, daß die parthenogenetischen Eier Männchen, die befruchteten Weibchen liefern, wie bei den Honigbienen und andern Hymenopteren. Auch Marchal beschränkt sich auf Vermutungen. Silvestri erst stellt fest, daß tatsächlich parthenogenetische Eier ïberhaupt zur Entwicklung gelangen; aber welches Geschlecht sie liefern, vermag er nicht zu entscheiden. Wie bei Encyrtus aphidivorus Mayr und Listomatix truncatellus Dalm. (entwicklungsgeschichtlich der Ageniaspis nahestehende Chalcidier) würden auch hier die unbefruchteten Eier Männchen liefern. Und dies scheint allgemein für die Chalcidier zu gelten: ich erwähne Entedon xanthopus Ratzeburg und Pentarthron carpocapsae Ashmead, für die Vasiliew (1907) den experimentellen Nachweis der Männchenbildung unbefruchteter Eier lieferte. Ich versuchte bei Ageniaspis ebenfalls experimentell vorzugehen: ein Evonymuszweig wurde in einen Mullsack eingeschlossen, mit Hyponomeuten besetz.t und, als diese abgelegt hatten, wurden cirka 300 unbefruchtete $ㅇ$ 우, die also aus rein »weiblichen « Raupen gewonnen waren, hinzugelassen. Leider aber gelang die Zucht nicht recht; denn ich erhielt nur sechs infizierte Raupen, von denen wieder nur in einer die Ageniaspis sich fertig entwickelten, und zwar waren es $\sigma^{\top} \sigma^{\top}$. Das Ergebnis stimmt zwar mit den Voraussagen überein, ist aber natürlich nicht beweiskräftig.

Was die Feinde der Ageniaspis betrifft, so habe ich in meinen Zuchtkäfigen Coccinellidenlarven den auf den Zweigen hin und herremnenden Imagines auflauern sehen; eine große rote Milbe, sowie ein Hemipteron, vermutlich eine Anthocoride, wurden mit einer gepackten 
Ageniaspis überrascht. Daß die Forficuliden sich durch Zerfressen der Hyponomeuta-Gelege indirekt als Feinde der Ageniaspis unangenehm bemerkbar machten, wurde schon oben erwähnt.

Aus den Raupen zog ich in großer Menge Mermitiden, wie demn auch Bugrion Mermis albicans v. Siebold als Parasiten der Hyponomeuta cognatella angibt; sie verließen die erwachsenen Raupen, von denen nur mehr ein leerer Hautsack übrig bleibt, und gingen aus Mangel an Feuchtigkeit bald zugrunde.

Eine Kolonie war stark infiziert mit Tachinen. Bugnion führt zwei unbestim.nte Spezies an. Herr H. Kraner-Niederoderwitz, ein vorzüglicher Kemner der Musciden, war so liebenswürdig, die von mir gezogenen zwei Arten zu bestimmen als Compsilura concinnata $\mathrm{Mg}$. und Prosopodes fugax Rdi. Die Compsilura-Art war bis dahin noch nicht aus Hyponomeuta cognatclla bekannt.

An Ichneumoniden führt Bugrion Herpestomus brunnicornis Wesm. an; ich erhielt aus den Puppen sehr zahlreich Agrypon anxium Wesm. Für die Bestimmung bin ich Herrn Prof. Dr. KrIeger zu Dank verpflichtet. Schließlich stellt die Familie der Chalcidier selbst außer Ageniaspis noch einen weitern Schmarotzer in einem (unbestimmten) Pteromalus.

Über das Verhältnis der Schmarotzer zueinander, im besondern zu Ageniaspis, will ich noch einiges anführen. Stechen die Ichneumoniden von Ageniaspis befallene Raupen an? Ich fand zwar wiederholt Raupen, die eine Ichneumonidenlarve beherbergten, aber nur einmal fand ich daneben gleichzeitig einen Keimschlauch. Vermutlich vermagr also das Ichneumonidenweibchen gesunde und infizierte Raupen zu unterscheiden; seine Larve würde ja auch wahrscheinlich der Konkurrenz der zahlreichen Ageniaspis-Larven unterliegen. Die Pteromalus dagegen gelangen sehr häufig neben der kleineren Ageniaspis zur vollen Entwicklung. Dies bezieht sich allerdings auf Hyponomeuta padclla L. (an Prumis spinosa in Freiburg a.d. U, gesammelt). In dieser Kolonie war ungefähr $1 / 4$ aller Raupen mit Ageniuspis infiziert und unter diesen schlïpften wieder aus jeder sechsten etwa neben den zahlreichen Agcniaspis 2, 3, eimmal auch 8 Pteromalus. Und zwar erschienen die Pteromalus in der Regrel einen Tag vor jenen.

Noch einige Worte schließlich iiber die Verbreitung der Ageniuspis. Rein tiergeographisch grenommen waren nicht nur die Hyponomeuten der hiesigen Auwälder, sondern auch die in der weiteren Umgebung Leipzigs, bei Grimma, Oschatz, Geithain und andern Orten ge:ammelten Raupen stets infiziert, und nicht nur cognatelle-, sondern 
auch padella- und einmal auch malinella Zeller-Raupen. Eine Ausnahme machten nur die in Anlagen und Gärten der Stadt selbst gefundenen Raupen verschiedenener Arten; sie waren immer gänzlich frei. Aber auch die relative Infektion innerhalb der einzelnen Nester ist außerordentlich stark, stärker anscheinend, als es Bugnion beobachtete; denn er rät etwa 20 Raupen zu zerreißen, um den Keimschläuchen mit Sicherheit zu begegnen. Ich traf stets schon unter den ersten zehn beliebig herausgegriffenen Tieren infizierte an von einem bis sechs im Maximum. (In meinen Zuchten war die Infektion selbstverständlich viel stärker.) Wesentliche spezifische Unterschiede (nach dem Wirt) ergaben sich nicht, doch müßte man, um hier genauer entscheiden zu können, umfangreichere, statistische Unterlagen haben. Im Großen und Ganzen kann man sagen, daß jede fünfte Raupe mit Ageniaspis-Keimschläuchen besetzt war.

\section{Allgemeiner Teil.}

Zum Schluß seien noch einige allgemeinere und vergleichende Bemerkungen gestattet, obschon Silvestri selbst (1909) eine zusammenfassende Darstellung aller Beobachtungen aus der Entwicklumgsgeschichte der Braconiden, Proctotrupiden, Chalcidier und Cynipiden in Aussicht gestellt hat.

Vorkommen der Polyembronie. Zunächst diirfte eine Zusammenstellung der bis jetzt bekannt gewordenen Fälle von Polyembryonie von Interesse sein. Es sind dies folgende Formen (diejenigen, bei denen der Zerfall nicht direkt verfolgt wurde, in Klammern):

Proctotrupiden: Polygnotus minutus Lindeman in den Larven von Cecidomyia destructor Say und C. avenae Marchal. 12-15 Individuen (Marchal 1904).

Chalcidier: Ageniaspis (Encyrtus) fuscicollis (Dalm.) Thoms. (MarCHAL 1904).

Ageniaspis (Encyrtus) fuscicollis (Dalm.) Thoms. (Marchal 1904), subspecies maysincola Silvestri in Prays oleellus Fbr. 10-15 Individuen. (Silvestri 1909.)

[Ageniaspis (Encyrtus) testaceipes (Ratzeburg) D. T. in Lithocolletis cramerella. Keimschlauch mit 12-15 Larven (Marchal 1904).].

Litomastix (Copidosoma) truncatellus (Dalm.) Thoms. in Raupen von Plusia gamma L. (und vielen andern). 1-2000 Individuen, daneben 100 und mehr provisorische, geschlechtslose Larven (Girard 1898, Silvestri 1906). 
Zur Entwicklungsgesch. des polyembryonalen Chalcidiers Ageniaspis usw. 469

[umbekannte Pteromalide aus Plusia moneta F. 》Mrriaden von Larven erfüllen die Raupe (G. Postel 1910)].

Copidosoma Buyssoni Meyr.

Zahl nicht genau bekannt; Zerfall der mmassa poliembrionale « in » masse poliembrionali secondarie«(Silvestri 1911).

Ohne Zweifel dürfte sich in Zukunft die Zahl der polyembryonalen Hymenopteren mehren und in dieser. Hinsicht mïssen wir unsre Aufmerksamkeit auf alle die Fälle lenken, wo einem Wirtstier zahlreiche Individuen von gleichem Geschlecht entschlüpfen; so scheint mir z. B unser geneiner Pteromalus puparum L. verdächtig, ïber den man in Ratzeburgs klassischen »Ichneumonen der Forstinsekten «, Bd. I und III Ausführliches findet. Freilich verweilt, wie der genannte Forscher beobachtete, das legende Weibchen einen ganzen Tag auf der Raupe und sticht sie offenbar wiederholt an, aber das schließt ja nicht aus, daß nicht eventuell die Eier doch polyembryonal zerfallen.

Erklärung der Polyembryonie. Eine Erklärung der Polyembryonie versucht allein MARchaL und es muß hier deshalb darauf eingegangen werden, weil sie mir unsern gegenwärtigen Erfahrungen gegenüber nicht stichhaltig zu sein scheint.

Marchal führt etwa folgendes aus: Die den Zerfall erleichternde Dotterarmut der Eier, der Überfluß an Nährmaterial, das bei der Zartheit des Chorions und durch die Ausbildung amniotischer Hüllen für das Wachstum des Eies, bzw. des Embryos nutzbar gemacht werden kann, - das sind Umstände, welche allein die Polyembryonie nicht bedingen können, da wir Entsprechendes auch bei monoembryonalen parasitischen Hymenopteren wiederfinden. Indem num aber MarchaL diese »polyembryonie spécifique " mit der 》polyembryonie expérimentale« (= Blastotomie) vergleicht, findet er, daß bei jener dieselben physikalischen Faktoren in Tätigkeit treten können, wie beim Experiment; und zwar seien die Möglichkeiten dazu eben nur bei der Entwicklung von Ageniaspis und Polygnotus gegeben.

So wird das Ei des Polygnotus - ein sonst nicht bekannter Fall - in den Magen der jungen Cecidomyia-Larve gelegt, wenn sie eben zu fressen beginnt; es sei somit plötzlich einem Milieu von anderm osmotischen Druck ausgesetzt. Dazu gesellt sich, dem Schuitteln beim Laboratoriumsversuch entsprechend, die mechanische Einwirkung einer lebhaften Peristaltik.

Das Ei der Ageniaspis fuscicollis anderseits erleidet eine ganz einzigartige Entwicklungsunterbrechung. Die junge Raupe hat, so 
stellt es sich MarchaL vor, samt dem in ihrer Leibeshöhle gelegenen Parasitenei während der langen Winterruhe eine gewisse Entwässerung erlitten - jedenfalls tritt, sobald die Raupe im April lebhaft zu fressen und zu wachsen begimnt, eine plötzliche und unvermittelte Störung des bisherigen KonzentrationsverhäItnisses von Parasiten- und Wirtsgewebe ein in dem Sinne, daß das Ei sich gradezu in einer hypotonischen Lösung befindet, und genau in dieser Periode tritt der Zerfall des Blastomerenhaufens in einzelne Morulae eir.

So verführerisch diese rein physikalische Erklärung ist - für Polygnotus ist die Analogie mit der künstlichen Polyembryonie kaum von der Hand zu weisen —, so kann sie für Ageniaspis nicht mehr in dem Umfange bestehen; denn wir haben Polyembryonie auch in Fällen kennen gelernt, wo die von MarchaL angeführten Bedingungen für eine Differenzierung des osmotischen Druckes (die lange Unterbrechung und die plötzliche Wiederaufnahme des Wachstums des Wirtes) nicht erfüllt sein können: die Ageniaspis von Prays nämlich hat entsprechend dem Wirtsschmetterling drei Generationen, von denen die beiden Sommergenerationen (April-Juni, Juli-September) sich kontinuierlich entwickeln. Dasselbe gilt von der Sommergeneration der Plusia gamma und ihres polyembryonalen Parasiten, des Litomastix truncatellus! Zudem tritt bei der praysincola die Polyembryonie erst in der schon fressenden Raupe ein.

Eine Erklärung der Polyembryonie in darwinistischem Sinne durch Zweckmäßigkeitsgründe erscheint mir auch nicht aussichtsreicher. Auf der einen Seite scheinen die Chancen zur Arterhaltung bei den polyembryonalen Arten nicht ungünstiger zu sein als bei den monoembryonalen parasitischen Hymenopteren; es kann für die im Kräuterwerk unter einem Evonymus-Strauch geschlïpften und so beweglichen Ageniaspis nicht schwer sein, ein Hyponomeuta-Gelege zu finden und, wem dies einmal erreicht ist, eine große Menge von Eiern unterzubringen; zudem braucht das Weibchen gar nicht befruchtet zu sein. Hier freilich geht anderseits ein so hoher Prozentsatz von Eiern, nämlich die in den Dotter abgelegten, zugrunde, daß man den Wert der Polyembryonie für die Erhaltung der Art nicht leugnen kann (für Litomastix würde ähnliches gelten; s. oben).

Vielleicht gelingt es an einer Unbergangsform oder etwa an einem fakultativ - je nach dem Wirtstier oder den Wirtsorganen - polyembryonalen Parasiten die spezifischen Bedingungen der Polyembryonie zu erkennen.

Aus der Embryologie unsrer Ageniaspis seien hier noch einige 
Punkte vergleichend betrachtet, so erstens das Verhalten der Rich tungskörper. Thre zeitweilige Erhaltung als »Kerne« einer amniosähnlichen Bildung muß geradezu als Charakteristikum aller bis jetzt genauer untersuchten polyembryonalen Formen betrachtet werden: bei Litomastix und bei Copidosoma Buyssoni wird nach Silvestri ganz Ähnliches beobachtet, wie bei Ageniaspis; auch bei Polygnotus liegen Kerne in der die Embryonen umgebenden gemeinsamen Nährmasse, nur sind die frühesten Stadien der Entwicklung, die allein über eine eventuell analoge Herkunft dieser Kerne entscheiden könnten, von Marchal nicht beobachtet worden.

Folgende Momente können in einzelnen als charakteristisch für die polyembryonalen Richtungskörper gelten:

1. das Zusammenfließen mehrerer (Ageniaspis, Litomastix, Copidosoma);

2. das Wachstum, sei es durch Vermehrung der Masse des durch Zusammenfließen entstandenen Kenes (Ageniaspis, Copidosoma), sei es durch, sogar mitotische Vermehrung dieses Kernes (Litomastix);

3. der schließliche Zerfall der Richtungskörper-Derivate am Ende des Embryonallebens (wie 1).

So merkwürdig diese Schicksale sind, eine vergleichende Betrachtung zeigt uns, daß die Möglichkeiten einer so exzessiven Entwicklung der Richtungskörper grade bei Insekten anderweit vielfach angedeutet sind.

Zunächst bleiben überhaupt die Richtungskörper der Insekten, ohne als besondere Zellen abgeschnürt zu werden, vielfach im Ooplasma, so bei Dipteren, Lepidopteren und - nach Korschelt und Heiders Lehrbuch - besonders (!) bei Hymenopteren.

Dann aber ist in vielen von diesen Fällen ein Zusammenfließen der Richtungskörper beobachtet worden: so von Hexking (1892) bei zahlreichen Insekten in verschicdenem Grade, im parthenogenetischen Ei der Honigbiene (Petrunkewitsch 1901), in den männchenliefernden Eiern von Tenthrediniden (Doxcaster 1906), bei den Chalcidiern Oophthora semblidis Aur. und Encyrtus aphidivorus Mayr (Silvestri 1909).

Ferner sind in Richtungskörpern Chromosomenbildungen bekannt geworden, die als Ansätze zu neuen Teilungen gedeutet werden können. 1 Hier sind die soeben erwähnten von Henking und Doncaster studierten Formen wieder zu nennen; Kahle (1908) beobachtete in den Richtungskörpern von Miastor Chromosomenschleifen und erblickt in dieser Bildung ein Zeichen von 》Aktivität «; er verweist auf die Be- 
obachtung Francottes (1898), daß bei der Polycladen Prostheceraeus vittatus der 1. Richtungskörper sich neben dem Ei bis zur Gastrula entwickle, und auf Petrunkewitschs (1901) vielfach stark angezweifelte Behauptung, wonach bei der Honigbiene die Richtungskörper an der Bildung der Keimbahn teilhaben.

Wenn wir endlich im Auge behalten, daß die polyembryonalen Richtungskörper, bzw. ihre Derivate nur eine provisorische (leider nicht genau bekannte) Bedeutung haben, $\mathrm{nm}$ schließlich wie alle andern zu degenerieren, so müssen wir sagen, es liegt hier nur eine extreme Steigerung gewisser, potentiell auch bei andern Insektenrichtungskörpern vorhandener Eigenschaften und nicht eime völlig isolierte, prinzipiell verschiedene Erscheinung vor.

Die Furchung. Der eingangs als partiell-total bezeichnete Mischcharakter der Furchung verliert für Ageniaspis seine Besonderheit, wenn scharf betont wird, daß, wie ich oben darstellte, die Entwicklung ihren Ausgang von der "Furchungszelle «nimmt; diese könnte als das eigentliche reife Ei betrachtet werden. Das Trophamnios wiirde dann als Homologon der typischen Richtungskörper mit Zellabschnürung zu betrachten sein. Bei Litomastix trennt sich erst nach vollendeter 1. Furchung das Embryonalplasma vom übrigen Ei ab, von Copidosoma sind die Details noch nicht bekannt gegeben.

Der Nucleolus. Schließlich seien dem Nucleolus einige Worte gewidmet. Er charakterisiert sich durch folgende Merkmale: Entstehung im hinteren Teil des jungen Ovarialeies - Wachstum unter offenbarer gelegentlicher Beteiligung des Keimbläschens, bis die definitive Größe im erwachsenen Ovarialei erreicht ist - Labilität, Vacuolisierung während der Reifungsvorgänge - Aufnahme in eine der beiden ersten Blastomeren - Teilungshemmung dieser Blastomere und fortschreitender Zerfall des Nucleolus, so daß er vom 4-Zellenstadium ab nicht mehr nachweisbar ist.

Es scheint, daß keines der in solcher Fülle als Dotterkerne und andre Einschlüsse im Ooplasma bekannt gewordenen Gebilde nach Herkunft, Wesen und Schicksal dem Nucleolus von Ageniaspis rergleichbar ist. Freilich, welchen Gesichtspunkt wir auch für eine vergleichende Betrachtung verwerten mögen, man muß sich dessen bewußt sein, daß alle mit so verhältnismäßig groben Methoden angestellten Untersuchungen ähnlicher Objekte nur beschränkten Vergleichswert haben. Ich möchte als Gegenbeispiel die Untersuchungen Jörannsens (1910) über das dem Dotterkern andrer Amphibien entsprechende »Konglomerat «im Proteus-Ei anführen: die raffiniertere Technik hat 
gezeigt, mit welch außerordentlich komplizierten Gebilden wir es hier unter Umständen zu tun haben; so beteiligen sich im Proteus-Ei nicht weniger als fünf verschiedene Substanzen an der Bildung des Konglomerates!

Ich beschränke mich daher auf einige wenige Andeutungen: nehmen wir z. B. die polare Chromatinanhäufung im Kern einerseits und die almähliche Entstehung des Nucleolus anderseits als eines extranucleären Körpers während des Eiwachstums, so erinnert das allenfalls an die mit Chromidienaustritt verbundenen Vorgänge, wie sie etwa im wachsenden $\mathrm{Ei}$ von Zoogonus (Goldschmidt 1905), von Ascidien (Schaxel 1909), Proteus (Jörgensen 1910) bekamnt geworden sind. Ein allmähliches Wachstum beschreibt auch Loyez (1909) vom »Dotterkern «des Eies von Pyrrhocoris apterus.

In seiner Struktur, speziell der starken Vacuolisierung während der Eireifung weist unser Nucleolus überraschende Ähnlichkeit auf mit gewissen »Metanucleolen « im Simne HaEckers, d. h. aus dem Keimbläschen ins Plasma ausgetretenen Nucleolen, wie sie von Aequorea ( $\mathrm{H}_{\mathrm{AE}}$ CKer 1892), Myzostoma (Wheeler 1897), Gastropoden (OBSt 1899) bekannt geworden sind. Auch der "Nucleolus «on Litomastix und, wenn man will - Silvestris Angaben widersprechen dieser Deutung wenigstens nicht - auch der von Ageniaspis (nach Silvestri NB.), Oophthora semblidis und Encyrtus aphidivorus (so in einem Referat von Buchner 1910), wäre unter die Metanucleolen zu rechnen; denn bei Litomastix liegt nach Silvestris Abbildungen und Beschreibung der Nucleolus in den jüngsten Eiern im Keimbläschen eingeschlossen, um später freizuwerden. Nun ist zwar, wie im Interesse der Klarheit nochmals hervorgehoben sei, die Entstehung des Ageniaspis-Nucleolus eine ganz andre, aber ein Blick auf die Bilder Silvestris von Litomastix oder auf die von OBst (1899) rom Metanucleus des Limax maximus (im Korschelt und Heider) wird eine unverkennbare Ähnlichkeit der Strukturen dartun.

Daß der Nucleolus von Ageniaspis nichts mit den immer nur in größerer Anzahl auftretenden und durch ihre liernähnliche Strulitur wohlcharakterisierten "Nebenkernen《 Blochmaxss zu tun lat, die allerdings gerade bei Hymenopteren so weit rerbreitet sind (Apis, Bombus, Xylocopa, Vespa, Polistes, Myrmica, Formica, Scolia), ist ohne weiteres einleuchtend.

So wird man am besten tun, sich BuchNer anzuschließen, der die Nucleolen von Ageniaspis und Litomastix, indem er ihre Aufnahme in die Furchungszellen und die Teilungshemmung als Wesentlichstes be- 
tont, unter dem Gesichtspunkt der Keimbahubestimmung betrachtet. Es ist zwar bis jetzt in keinem der beiden Fälle gelungen, die die Nucleolensubstanz enthaltenden Zellen bis in die Gonade der jungen Larve zu verfolgen und es scheint mir auch schwierig, sich die Verteilung dieser Keimbahnzellen auf die vielen Embryonen vorzustellen (Tausende bei Litomastix!), aber das, was beobachtet werden konnte, entspricht im Prinzip durchaus den Vorgängen bei der Keimbahnbestimmung von Oophthora und Encyrtus. Mehr wagt auch Silvestri nicht zu behaupten; was ich deshalb hervorheben möchte, weil man in der Literatur Litomastix und Ageniaspis ohne weiteres als Formen mit Keimbahnbestimmung angeführt finden kann, obwohl es doch nur mit Vorbehalt gilt.

Ian könnte vielleicht an eine rudimentäre, durch Polyembryonie nur noch in ihren Anfängen erhaltene und durch die (sekundärc) totale Furchung modifizierte (Aufnahme der Substanz in eine der beiden ersten Furchungszellen) Keimbahnbestimmung denken.

Jedenfalls spricht Buchner (1910) wiederholt die Vermutung aus, es möchten die Nucleolen der von Silvestri untersuchten Chalcidier nicht dem Keimbläschen entstammen, wie Silvestri es bei Litomastix beobachtete und bei den andern vermutet, vielmehr seien sie von außen aus Nähr- oder Epithelzellen in das Ei hineingelangt. So hat er selbst für die Keimbahneinschlïsse von Sagitta (1910) einen fremdzelligen Ursprung nachgewiesen und sucht ihn für die aller andern Formen wahrscheinlich zu machen; wie deun später KüHs (1911) bei Polyphemus pediculus die Derivate einer Nährzelle als kontinuierlichen Bestandteil der Geschlechtszellen feststellen konnte.

Durch die vorstehende Untersuchung ist Buchners Vermutung nur insofern bestätigt, als bei Ageniaspis wenigstens der Nucleolus nicht durch einfachen Austritt aus dem Keimbläschen entsteht; anderseits aber ist trotz der unfangreichen Aufnahme fromdzelligen Materials durch das wachsende Ei kein Anhalt für die ausschließliche Entstehung des Nucleolus aus diesen Elementen gewonnen worden.

\section{Zusa m menfassung..}

Die Ovarialtuben des Ageniaspis fuscicollis sind in ihrem vorderen Teil typisch polytroph, im hinteren, erweiterten Teil enthalten sie freie Follikel.

Das Keimbläschen des wachsenden Eies zeigt anfangs eine polare Chromatinanhäufung, dann eine gleichmäßige Verteilung der chromatischen Substanz; es löst sich auf unter Bildung zahlreicher Chromatinkörper, die zu wahrscheinlich vier parallel der Eilängsachse gelegenen 
Chromosomen zusammentreten; schließlich aber vereinigen sich die Chromosomen wieder zu einem kompakten Körper.

In bezug auf Reifung, Furchung und Schicksal der Richtungskörper wurden die Angaben Silvestris im Prinzip bestätigt, nur in einigen Punkten erweitert: die frühzeitige Differenzierung von Trophamnios und Furchungszelle, die kompliziertere Umwandlung der Richtungskörper, die Differenzierung des Trophamniosplasma in eine Innenmasse und eine Außenzone.

Was dagegen die Beobachtungen am Nucleolus betrifft, so möge es, um eine Wiederholung zu vermeiden, gestattet sein, auf die im allgemeinen Teil, Seite 472 bereits gegebene Zusammenstellung zu verweisen.

Die Ageniaspis-Eier vermögen sich nur unter Vermittlung der Hyponomeuta-Embryonalzellen zu entwickeln; daher gehen die im Dotter gelegenen Eier auf eine charakteristische Weise zugrunde.

Gelegentlich war das Trophammiosplasma der Keimschläuche mit wahrscheinlich aus der Wirtsraupe stanımenden bakterienähnlichen Gebilden erfüllt.

Die zweite Chitinschale des Hyponomeuta-Eies umschließt dieses vollständig.

Leipzig, im Juni 1913.

\section{Literaturverzeichnis.}

A. Berlese, Gli Insetti. Milano 1909.

G. Braxdes, Germinogonie, eine neue Art der ungeschlcehtlichen Fortpflanzung. Zeitschr. f. d. ges. Naturw. Halle LXX. 1898.

P. Buchner, Das accessorisehe Chromosom in Spermatogenese und Orogenese dẹr Orthopteren, zugleich ein Beitrag zur Kenntnis der Reduktion. Arch. f. Zellforseh. Bd. III. 1909.

- Die Schicksale des Keimplasmas der Sagitten in Reifung, Befruehtung, Keim. bahn, Orogenese und Spermatogenese. Festschr. z. 60. Geburtstag R. Hertwigs. Bd. I. 1910.

- (Referat über Silvestris Arbeiten.) Arch. f. Zellforsch. Bd. V. 1910.

- Studien an intracellulären Symbionten. 1. Dic intracellulären Symbionten der Hemipteren. Arch. f. Protistenkunde. Bd. XXVI. 1912.

E. Bugriox, Recherches surr le développement postembryonaire, l'anatomie et les mœurs de l'Eneyrtus fuscicollis. Recueil zoologique suisse. V. 1891.

L. Doxcaster, On the maturation of the unfertilised egg and the fate of the polar bodics in the Tenthredinidae. Quart. Journ. Micr. Sc. (2.) Vol. XLIX. 1906.

P. Francotte, Recherches sur la maturation, la fécondation et la segmentation chez les Polyclades. Arcl. d. Zool. Expér. 3e sér. T. VI. 1898. 
A. GIARD, Sur le développement de Litomastix truncatellus Dalm. Bull. Soc. Entom. France. 1898.

R. Goldschimd, Eireifung, Befruchtung und Embryonalentwicklung des Zoogonus mirus. Zool. Jahrb., Abt. f. Anat. Bd. XXI. 1905.

J. Gross, Untersuchungen über die Histologie des Insektenovariums. Ibidem. Bd. XVIII. 1903.

V. HALCker, Die Furchung des Eies von Aequorea Forskalea. Arch. f. Mikr. Anat. Bd. XL. 1892 .

M. Heidenhain, Plasma und Zelle. Jena 1907.

H. Henking, Untersuchungen über die ersten Entwicklungsvorgänge in den Eiern der Insekten. III. Spezielles und Allgemeines. Zeitschr. f. wiss. Zool. Bd. LIV. 1892.

L. F. Henneguy, Les Insectes. Paris 1904.

R. Hexmoxs, Süßwasser-Hymenopteren aus der Umgebung Berlins. Deutsche Entom. Zeitschr. 1908.

M. Jörgensen, Zur Entwicklungsgeschichte des Eierstockeies von Proteus anguineus. Festschr. z. 60. Geburtstag R. Hertwigs. Bd. I. 1910.

W. Kahle, Die Paedogenese der Cecidomyiden. Zoologica. Hft.55. 1908.

Korschelt und HEIDER, Lehrbuch der vergleichenden Entwicklungsgeschichte der wirbellosen Tiere. Allgem. Teil. 1. u. 2. Aufl. Jena 1903.

A. KüHN, Über determinierte Entwicklung bei Cladoceren. Zoolog. Anzeiger. Bd. XXXVIIT. 1911.

M. Loyez, Le corps vitellin de l'oocyte de Pyrrhocoris apterus. Arch. Anat. Micr. Paris. T. X. 1909.

P. Marchal, Recherches sur la biologie et le développement des Hyménoptères parasites. 1. La polyembryonie spécifique ou germinogonie. Arch. d. Zool. Expér. IVe sér. T. II. 1904.

G. Mayr, Die europäischen Encyrtiden. Verh. d. Zool.-Bot. Ges. Wien. Bd. XXV. 1876.

P. Oвsт, Untersuchungen über das Verhalten der Nucleolen bei der Eibildung einiger Mollusken und Arachnoiden. Zeitschr. f. wiss. Zool. Bd. LXVI. 1899.

W. Paulcke, Über die Differenzierung der Zellelemente im Ovarium der Bienenkönigin (Apis mellifica). Zool. Jahrb., Abt. f. Anat. Bd. XIV. 1901.

A. Petrunkewitsch, Dic Richtungskörper und ihr Schicksal im befruchteten und unbefruchteten Bienenei. Ibiclem.

G. Postel, Premiers états de Plusia moneta F.; polyembryonie de son parasite. Bull. Soc. Entom. France. 1910.

Ratzebura, Die Ichneumonen der Forstinsekten. 3 Bde. Berlin 184t-52.

S. Schaxer, Die Morphologie des Eiwachstums und der Follikelbildungen bei den Ascidien. Arch. f. Zellforsch. Bd. IV. 1910.

W. SchleIP, Die Reifung der Eier von Rhodites rosae L. und einige allgemeine Bemerkungen über die Chromosomen bei parthenogenetischer Fortpflanzung. Zool. Anz. Bd. 35.

F. Silvestri, Contribuzioni alla conoscenza biologica degli Imenotteri parassiti. I. Biologia del Litomastix truncatellus Dalm. Annali della R. Scuola Sup. d'Agricoltura di Portici. Vol. VI. 1906. 
F. Silvestri, Contribuzioni alla conoscenza biologica degli Imenotteri parassiti. II. Sviluppo dell'Ageniaspis fuscicollis Dalm. e note biografiche. Bolletino del Laboratorio di Zoolog. Gen. et Agraria della R. Scuola Sup. d'Agricoltura in Portiei. Vol. III. 1909.

- Notizie preliminari sullo sviluppo del Copidosoma Buyssoni Meyr. Rendiconto della nona assemblea generale ordinaria e del Convegno dell'Unione Zoologiea Italiana in Napoli. Florenz 1911.

J. VAssilıEw, Über nene Fälle von Parthenogenese in der Familie der Chalcidier. Zeitschr. f. wissensch. Insektenbiologie. Bd. III. 1907.

W. M. Wheeler, The maturation, fecondation and early cleavage of Myzostoma glabrum. Arch. de Biol. T. XV. 1897.

\section{Erklärung der Abbildungen.}

Sämtliche Figuren sind, wo nicht anders angegeben, als optische Schnitte bei Leitz homog. Immersion 1/12 und Ocular 4 mit dem AbBeschen Zeichenapparat entworfen. - Die photographischen Aufnahmen verdanke ich der Liebenswürdigkeit des Herrn Dr. G. Grimpe-Leipzig.

\section{Zeichenerklärung:}

I, erste Eischale des Hyponomeuta-Eies; $n l s$, Nucleolus;

II, zweite Eischale des Hypon.-Eies; $n z$, Nährzelle;

Ag, Ageniaspis-Ei;

$a$, Amnios;

$b l$, Furchungszelle;

$b l_{1}, b l_{2}$, erste, zweite Blastomere bzw.

deren Derivate;

ch, Chorion;

E, Hyponomenta-Embryo;

ekt, ektoplasmatische Zone des Trophamnios;

ent, entoplasmatische Zone des Trophamnios;

epz, Epithelzelle;

$h$, Hülle;

$m$, Mikropyle;

$o_{1}, o_{2}$, Kern (-Figuren) der Oocyte erster bzw. zweiter Ordnung;

$o_{3}$, weiblieher Vorkern;

$p_{1}, p_{2}$, erster bzw. zweiter Richtungskörper;

$p . h$, peritoneale Hülle;

p.n, Paranucleus;

$s$, Serosa;

$s p$, Spermatozoon bzw. männlicher Vorkern;

t.p, Tuniea propria der Eirölıren;

tr, Trophamnios;

r, Vacuole;

$x$, »abgestoßenes Chromatin «。

\section{Tafel XV.}

Fig. 1-10. Das Ovarialei. - In den Fig. 3, 5, 6, 7, 10 sind nur die Eizellen gezeichnet.

Fig. 1. Polare Chromatinanhäufung im Kern. - Das Ei abgerundet, Eiund Nährkammer sind gebildet.

Fig. 2. Polare Chromatinanhäufung. - Das Ei beginut sich zu strecken. Teilung einer Epithelzelle.

Fig. 3. Polare Chromatinanhäufung begimt $z u$ schwinden; im hinteren Teil des Eies Granulationen und Nucleolus. 
Fig. 4. Nucleolus größer geworden, im Kern das Chromatin gleichmäßiger verteilt. - Das Ei zeigt Anfänge der Einschnürung in der Mitte. Epithelzellen abgeflacht. Aufnahme einer Nährzelle.

Fig. 5. Auflösung des Kernes: zahlreiche Chromatinkörper in einem hellen Hof. Nucleolus wächst weiter. Vacuole. Chorion am Hinterende, Ei noch mehr gestreckt.

Fig. 6. Chromatinkörper rücken nach dem Centrum. Fadengerüst. Dazwischen das »abgestoßene Chromatin «.

Fig. 7. Chromatinkörper ordnen sich parallel; das »abgestoßene Chromatin « an den Polen der Kernfigur.

Fig. 8. Verschmelzung der Chromatinkörper zu den "Chromosomen «. Nährkanmer fast resorbiert.

Fig. 9. Die "Chromosomen « schließen sich zusammen. Der helle Hof schwindet. Nucleolus erwachsen, einheitlich geworden, vacuolisiert. Granulationen geschwunden. Ei erwachsen. Nährkammer geschwunden.

Fig. 10. Ei aus dem Calyx, zusammengestaucht. Am eingedellten Vorderpol Mikropyle. Kern kompakt geworden.

Fig. 11-14. Die Reifung.

Fig. 11. Erste Reifungsteilung. Anaphase.

Fig. 12. Erste Reifungsteilung. Telophase.

Fig. 13. Zweite Reifungsteilung, Teilung des ersten Richtungskörpers; beide in Anaphase. Spermatozoon.

Fig. 14. Zweite Reifungsteilung, aber die Teilung des ersten Richtungskörpers (am vorderen Pol gelegen, Teilungsebene gedreht) weiter fortgeschritten, als die zweite Reifungsteilung (Eimitte). Chorion.

Fig. 15. Querschnitt durch eine Ovarialtube in der Höhe der Wachstumszone. Drei von ihrem Follikelepithel umgebene Eier in verschiedener Höhe getroffen; alle drei von der gemeinsamen peritonealen Hülle umschlossen.

\section{Tafel XVI.}

Fig. 16. Zweite Reifungsteilung, typisches Verhalten. An Vorderpol: zweiter Richtungskörper, im Centrum: Teilungsfigur des ersten Richtungskörpers (Teilungsebene gedreht), im hinteren Teil Eikern und Nucleolus. Plasmadifferenz.

Fig. 17. Reifes Ei. - Im Polarplasma am Vorderpol zweiter Richtungskörper; dann die beiden Tochterkerne des ersten Richtungskörpers. Im Embryonalplasma: der große Eikern, der Nucleolus.

Fig. 18. Die Befruchtung. - Im Embryonalteil die beiden Vorkerne: über dem einen der Nucleolus.

Fig. 19-27. Die Furchung.

Fig. 19-21. Umwandlung der Richtungskörper. Furchungszelle mit Nucleolus und Kern, und Trophamnios.

Fig. 19. Ein Richtungskörper löst sich in Körnchenreihen auf.

Fig. 20. Zahlreiche »Kerne «.

Fig. 21. Die »Kcrne «fließen zusammen. Prophase der ersten Furchung.

Fig. 22. Telophase der ersten Furchungsteilung, olıne Zellbildung. Daneben Nucleolus.

Fig. 23. Zwei-Blastomerenstadium, in einer der Nucleolus. Trophamnios mit dem »Paranucleus «. 
Zur Entwicklungsgesch, des polyembryonalen Chaleidiers Ageniaspis usw. 479

Fig. 24. Zwei-Blastomerenstadium, die nucleolusfreie Blastomere in Teilung begriffen, Nucleolus extrem groß.

Fig. 25. Drei-Blastomerenstadium. Die mit dem Nucleolus behaftete Zelle hat sich noch nicht geteilt.

Fig. 26. Nueleolushaltige Blastomeren vom 2-Zellenstadium.

Fig. 27. Nucleolushaltige Blastomeren vom 3-Zellenstadium, Auflösung des Nucleolus.

Fig. 28. Schnitt dureh ein Ei aus der Hyponomeuta-Raupe im Oktober mit der von der Raupe stammenden Hülle. Eeto- und entoplasmatischer Teil des Trophamnios. Paranucleus von Plasmasträngen durehsetzt. Blastomeren in Gruppen.

Fig. 29. Stück eines Schnittes dureh ein Hyponomeuta-Gelege mit Eiern von Ageniaspis fuscicollis im Dotter. - Leitz Oc. 3, Obj. 3. 


\section{Vita.}

Der Verfasser dieser Arbeit, Hermann Friedrich Martin, wurde am 23. Dezember 1887 in Wendiseh-Rottmannsdorf bei Zwickau als Sohn des Pfarrers Oscar Martin geboren und evangelisch-lutherisch getauft. Seine erste Vorbildung erhielt er in der Volksschule zu Obercunnersdorf bei Löbau, später bei seinem Vater. Osterm 1898 trat er in die Quinta des Gymnasiums zu Zittau ein, das er 1906 unit dem Reifezeugnis verließ, um sich dem Studium der Naturwissenschaften zu widmen. Er besuchte von Ostern 1906 bis Ostern 1907 die Universität Leipzig, dann zwei Semester die Universität Berlin und studiert seitdem wieder in Leipzig.

Seine akademischen Lehrer waren in Berlin: Baur, Brauer, Defgener, E. Fischer, Heymons, W. Macnus, Neuberg, F. E. Schulze, - in Leipzig: Barth, v. Brücke, Chun, Credner, Correns, O. Fisciner, Hantzsch, Hölder, Jungmann, Pfeffer, Pinne, Simroth, Spranger, Steche, zur Strassen, Volkelt, Wagner, Wiener, Woltereck, Wundt, Zirkel. 
1.

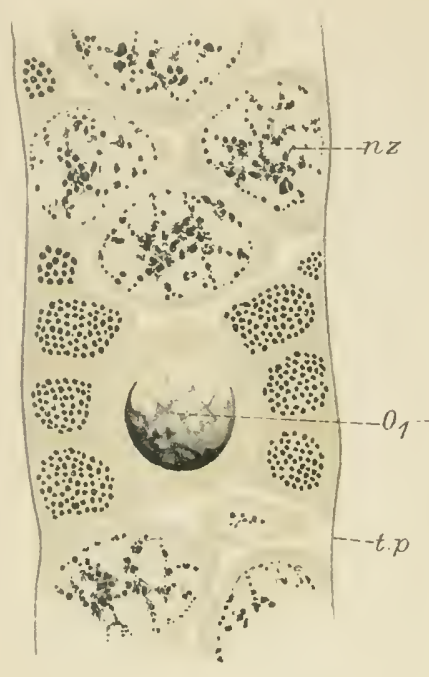

2.
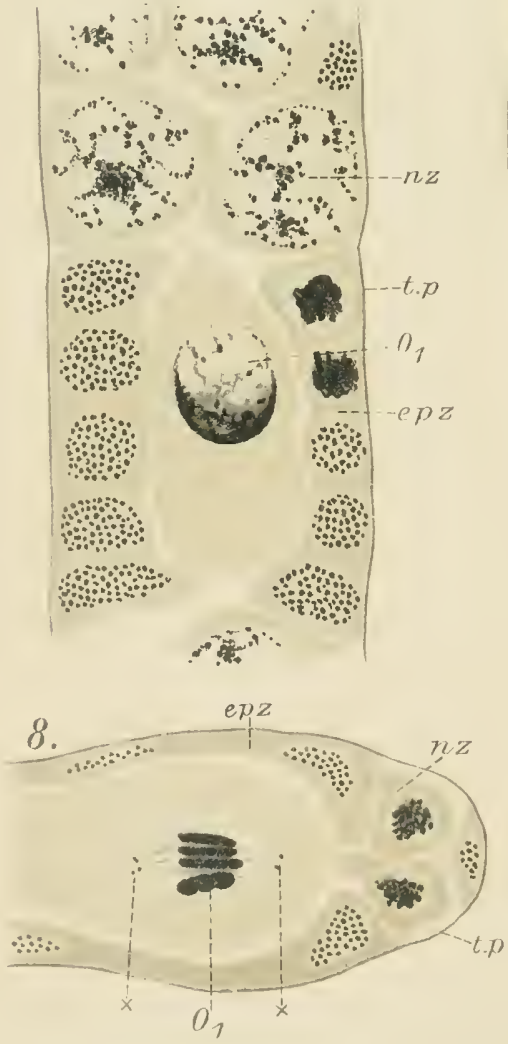

4.

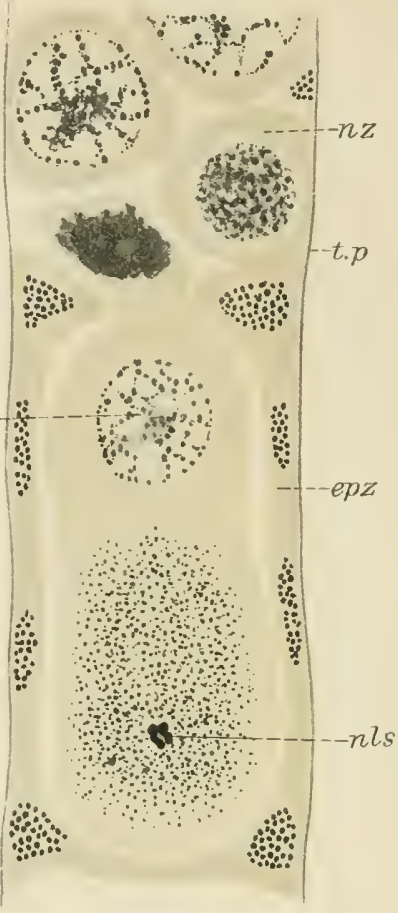

5.

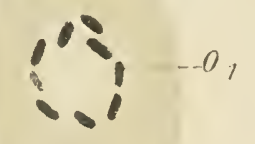

6.

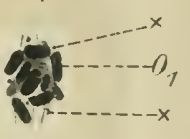

7.

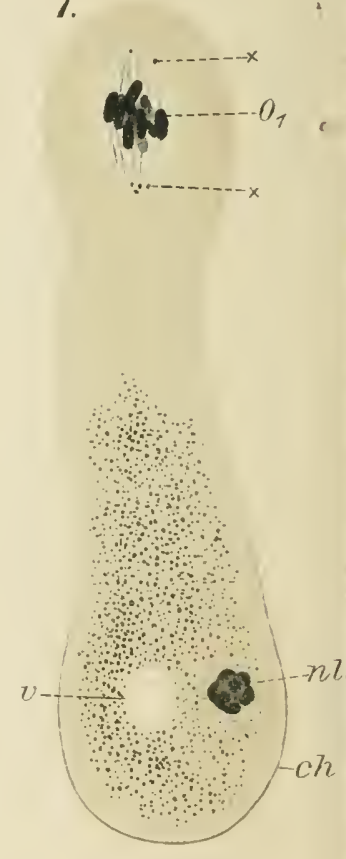

3.

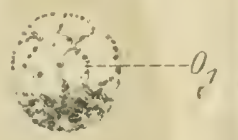




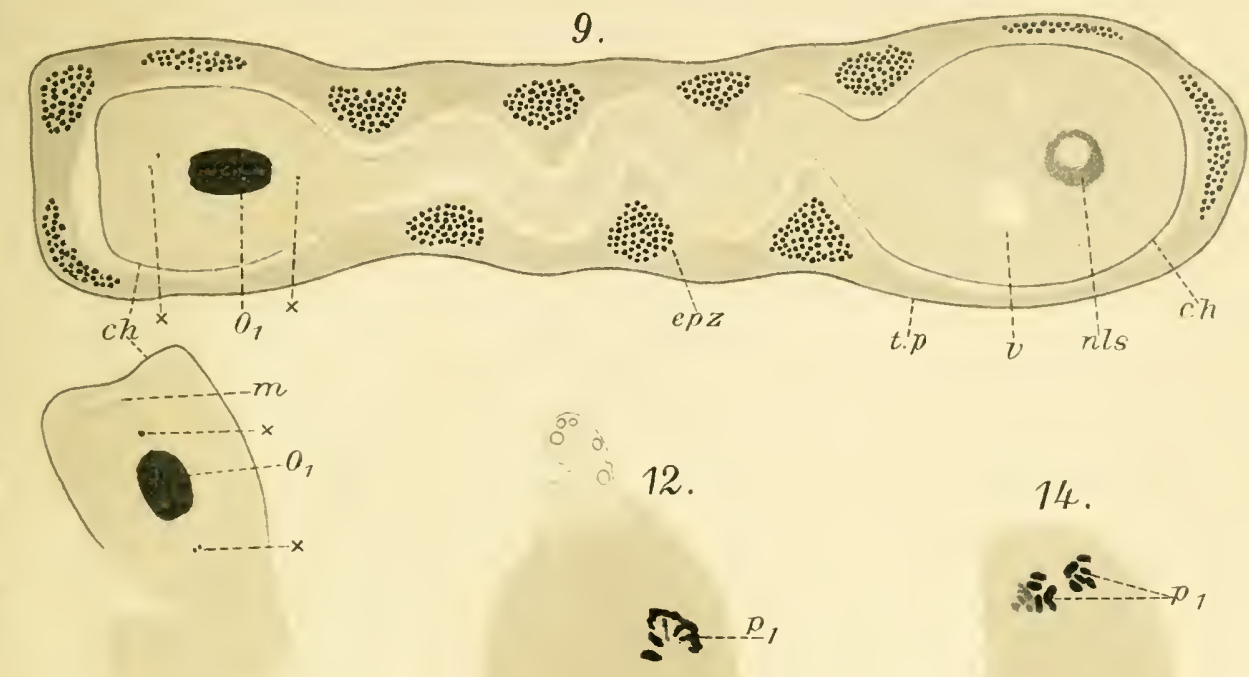

10.
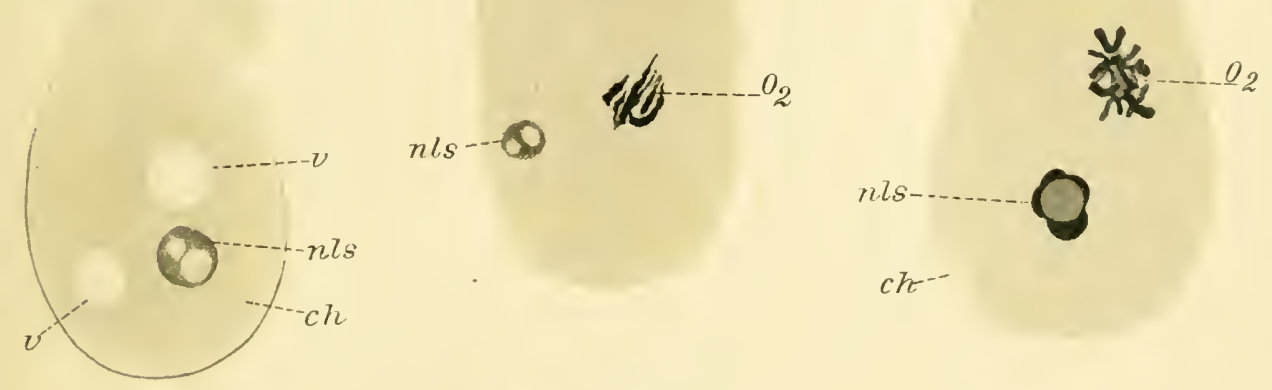

11.

?

$n l s--0$ ch-

EN $p_{1}$

13.

$|1|_{1 \ldots, \ldots-1}$

(ii)

1) $-0^{3}$

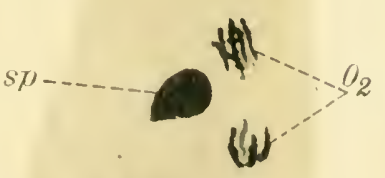

$e p^{L} z$

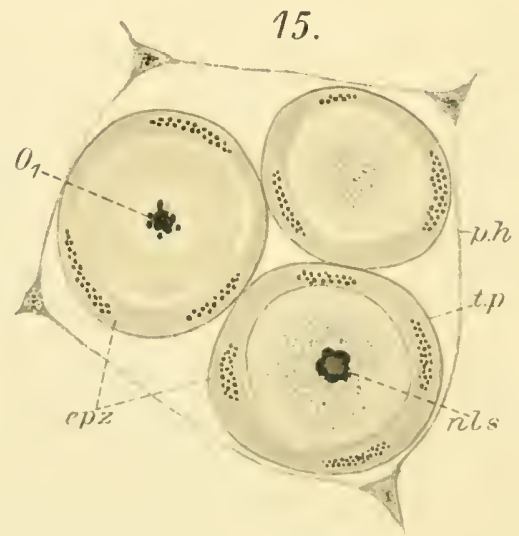





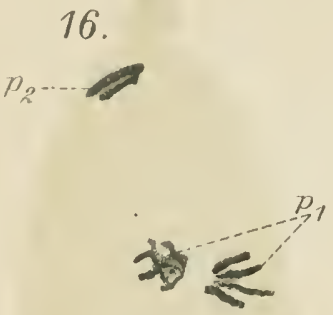

$n l s$

19.

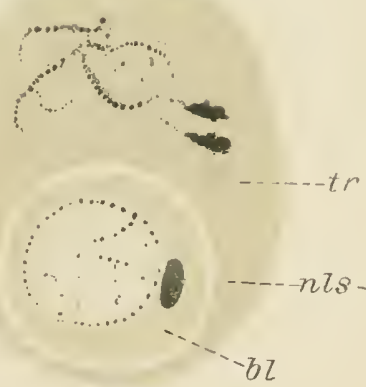

20.
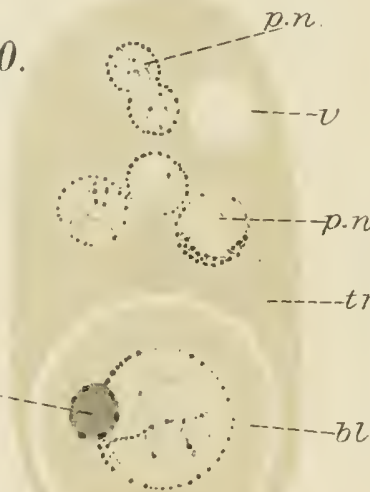

17.

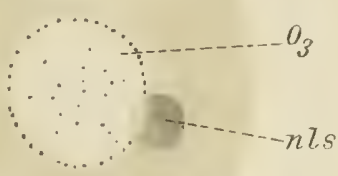

18.
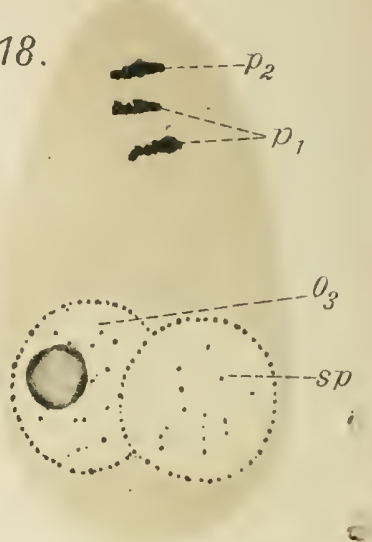

21.

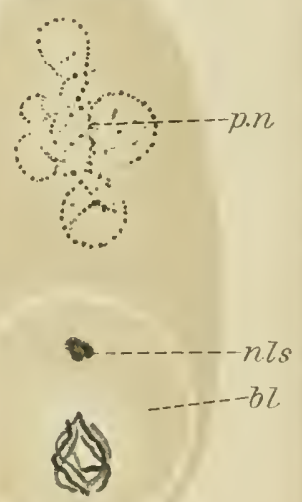

22.

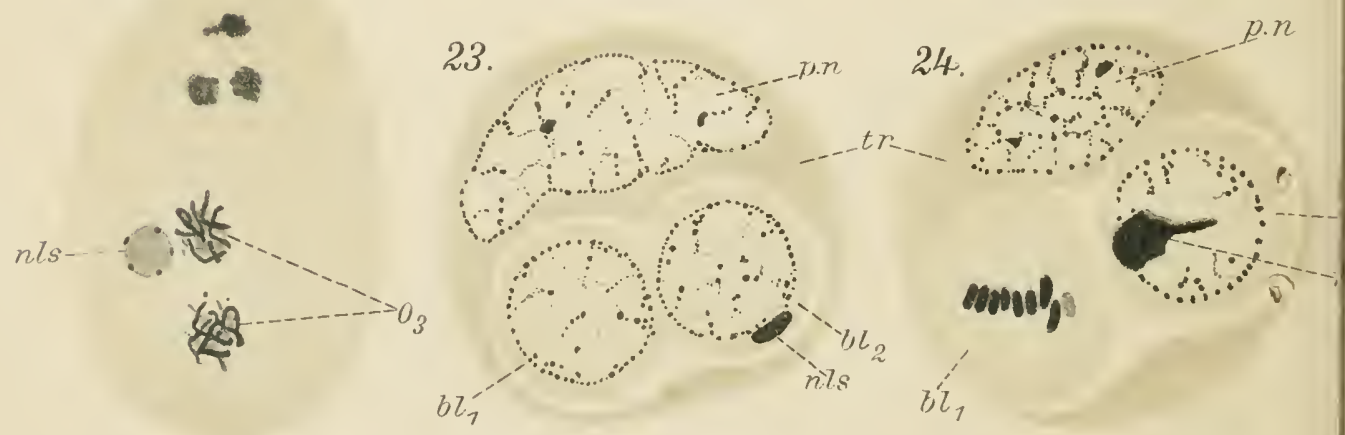




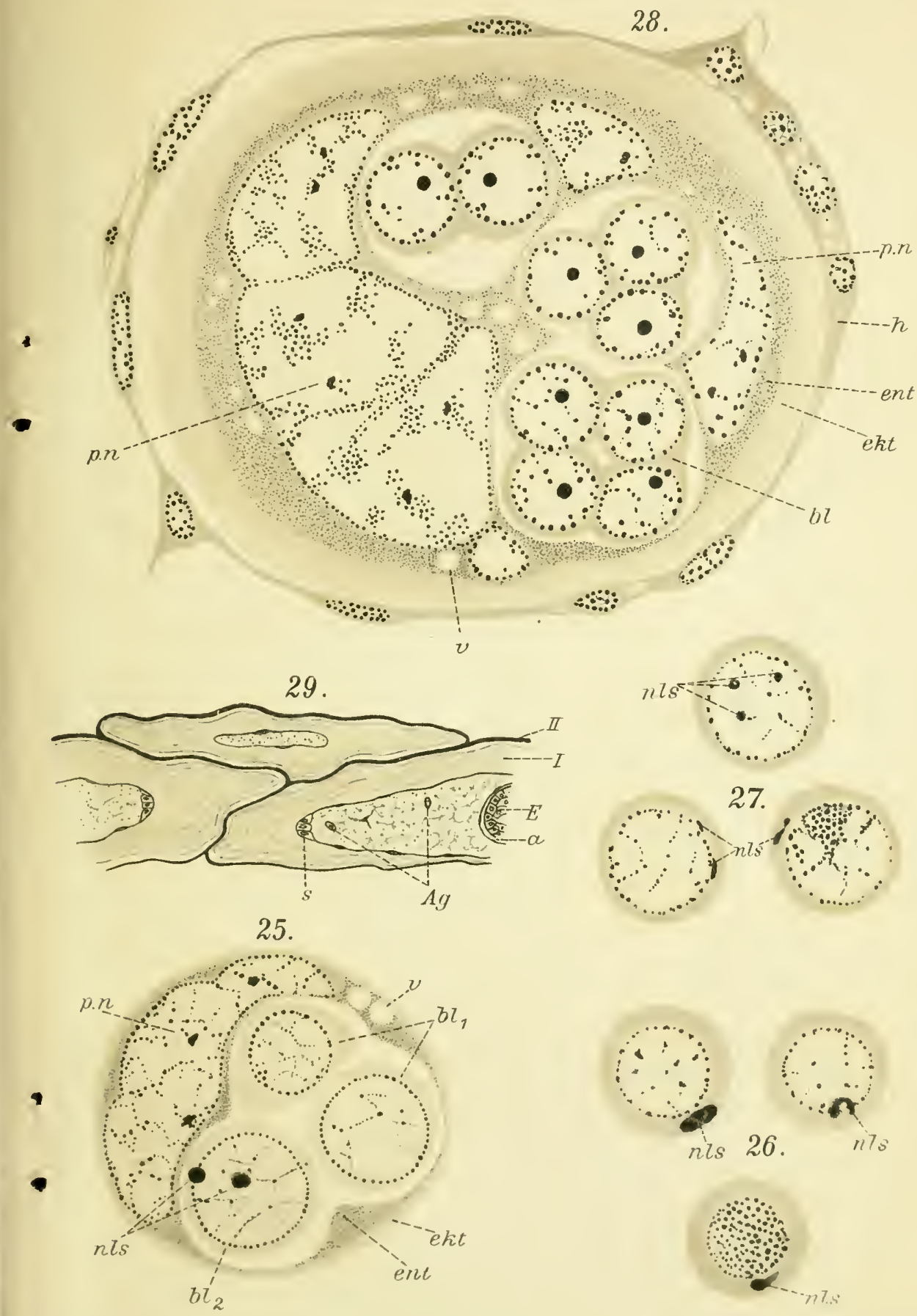


